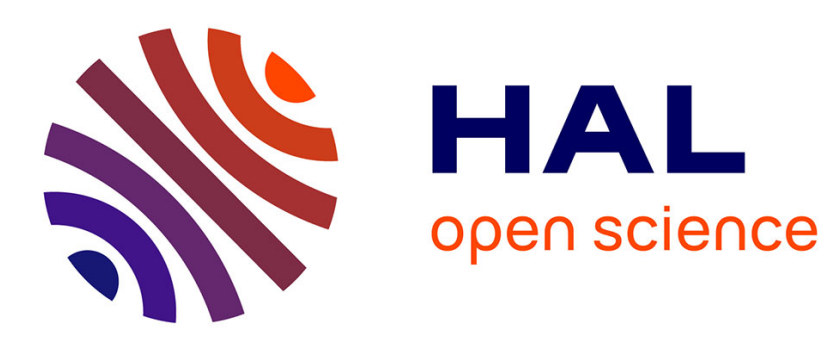

\title{
Deformation of the North American Plate interior from a decade of continuous GPS measurements
}

\author{
E. Calais, J.Y. Han, C. Demets, J.-M. Nocquet
}

\section{To cite this version:}

E. Calais, J.Y. Han, C. Demets, J.-M. Nocquet. Deformation of the North American Plate interior from a decade of continuous GPS measurements. Journal of Geophysical Research, 2006, 111 (B6), 23 pp. 10.1029/2005JB004253 . hal-00407587

\section{HAL Id: hal-00407587 https://hal.science/hal-00407587}

Submitted on 4 May 2021

HAL is a multi-disciplinary open access archive for the deposit and dissemination of scientific research documents, whether they are published or not. The documents may come from teaching and research institutions in France or abroad, or from public or private research centers.
L'archive ouverte pluridisciplinaire HAL, est destinée au dépôt et à la diffusion de documents scientifiques de niveau recherche, publiés ou non, émanant des établissements d'enseignement et de recherche français ou étrangers, des laboratoires publics ou privés. 


\title{
Deformation of the North American plate interior from a decade of continuous GPS measurements
}

\author{
E. Calais, ${ }^{1}$ J. Y. Han, ${ }^{2}$ C. DeMets, ${ }^{3}$ and J. M. Nocquet ${ }^{4}$ \\ Received 29 December 2005; revised 21 February 2006; accepted 28 February 2006; published 10 June 2006.
}

[1] A combination of two independent geodetic solutions using data from close to 300

continuous GPS stations covering the central and eastern United States shows that surface deformation in the North American plate interior is best fit by a model that includes rigid rotation of North America with respect to ITRF2000 and a component of strain qualitatively consistent with that expected from glacial isostatic adjustment (GIA). After correcting for the North American plate motion, residual horizontal velocities show a north-to-south deformation gradient of $\sim 1 \mathrm{~mm} \mathrm{yr}^{-1}$, mostly localized between 1000 and $2200 \mathrm{~km}$ from the GIA center, corresponding to strain rates of about $10^{-9} \mathrm{yr}^{-1}$. At distances farther than $2100 \mathrm{~km}$ from the GIA center, horizontal residual velocities are random with no evidence for regions of elevated strain rates. In particular, we find no detectable residual motion at the 95\% confidence level in the New Madrid Seismic Zone, where the average weighted misfit of $0.7 \mathrm{~mm} \mathrm{yr}^{-1}$ is the same as the weighted misfit of our rigid plate model. Vertical velocities show (1) a maximum uplift rate of $10 \mathrm{~mm} \mathrm{yr}^{-1}$ at the assumed GIA center, (2) a hinge line located $1500 \mathrm{~km}$ from that center, and (3) a subsidence rate up to $1.4 \mathrm{~mm} \mathrm{yr}^{-1}$ in the forebulge, with a maximum located about $2000 \mathrm{~km}$ from the GIA center. Our results have the potential to better constrain glacial isostatic adjustment models and contribute to a better definition of stable North America for tectonic and geodetic applications.

Citation: Calais, E., J. Y. Han, C. DeMets, and J. M. Nocquet (2006), Deformation of the North American plate interior from a decade of continuous GPS measurements, J. Geophys. Res., 111, B06402, doi:10.1029/2005JB004253.

\section{Background}

[2] Large earthquakes within stable plate interiors are direct evidence that significant amounts of elastic strain can accumulate along geologic structures far from plate boundary faults, where the vast majority of seismic energy is released. The 1811-1812 New Madrid events in the Mississippi valley are classical examples of large intraplate earthquakes [e.g., Nuttli, 1983; Johnston, 1996; Hough et al., 2000] (Figure 1), as is the 1905-1957 sequence of four M8 and greater earthquakes in Mongolia [Baljinnyam et al., 1993]. Because significant intraplate earthquakes are infrequent and strain rates in continental interiors are so low, neither the rates and pattern of intraplate strain are well constrained, nor are the mechanism(s) responsible for strain accumulation and release on faults inside plates.

[3] On the basis of the scatter of GPS station velocities with respect to the predictions of best fitting angular

\footnotetext{
${ }^{1}$ Department of Earth and Atmospheric Sciences, Purdue University, West Lafayette, Indiana, USA.

${ }^{2}$ Department of Geomatics, Purdue University, West Lafayette, Indiana, USA.

${ }^{3}$ Department of Geology and Geophysics, University of WisconsinMadison, Madison, Wisconsin, USA.

${ }^{4}$ Centre National de la Recherche Scientifique, UMR6526 Géosciences Azur, Valbonne, France.

Copyright 2006 by the American Geophysical Union. 0148-0227/06/2005JB004253\$09.00
}

velocity vectors, prior geodetic studies have established an approximate upper bound of $2 \mathrm{~mm} \mathrm{yr}^{-1}$ for residual motions across the central and eastern United States [e.g., Argus and Gordon, 1996; Dixon et al., 1996; Newman et al., 1999; Kogan et al., 2000; Sella et al., 2002; MárquezAzúa and DeMets, 2003]. Gan and Prescott [2001] additionally reported evidence for elevated strain in the south central United States. Though slow by the standards of most plate boundary zones, deformation of $2 \mathrm{~mm} \mathrm{yr}^{-1}$ nonetheless implies significant seismic hazard over a period of centuries to millennia if it represents elastic strain that accumulates over a several hundred kilometer-wide zone such as the New Madrid Seismic Zone. Practical considerations thus motivate efforts, including our own, to better quantify local-, regional-, and possibly plate-scale strain from the North American plate GPS velocity field.

[4] Deglaciation of the continental interior following the last ice age has also affected the present velocity field through the still incomplete viscoelastic response of the mantle to the removal of the Laurentide ice sheet that covered Canada and parts of the northern United States until 20,000 years ago [e.g., Peltier, 1986; Davis and Mitrovica, 1996]. The predicted horizontal surface responses to ice unloading for a range of assumed mantle viscosity structures and likely spatial and temporal scenarios for deglaciation vary from no faster than $1 \mathrm{~mm} \mathrm{yr}^{-1}$ (e.g., the ICE-3G/VM1 model of Peltier [1994]) to as fast as $\sim 2 \mathrm{~mm} \mathrm{yr}^{-1}$ (e.g., the ICE-4G/VM2 model Peltier [1996]) 


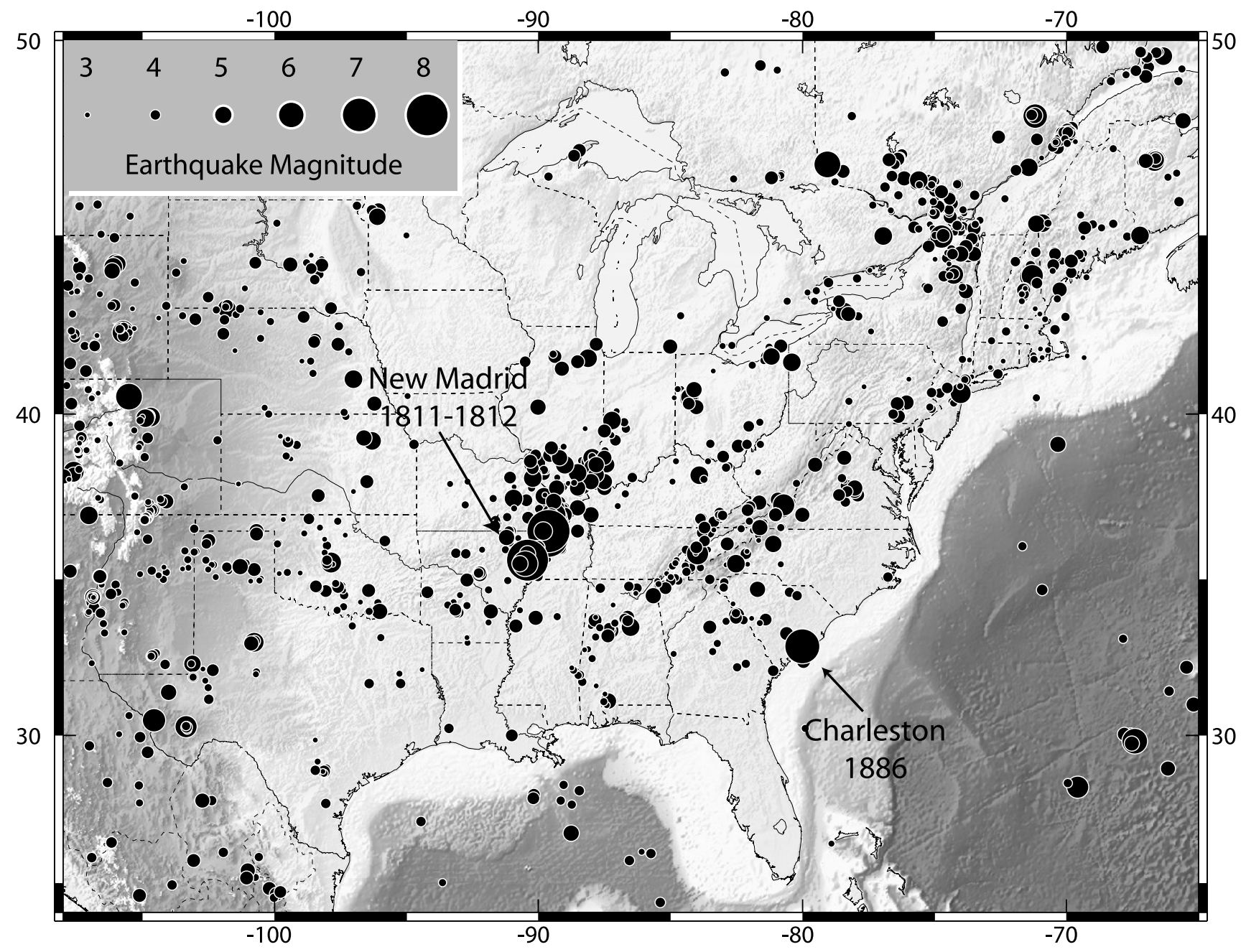

Figure 1. Topography and seismicity in the midcontinent, limited to earthquakes with magnitudes greater than 3 in the National Earthquake Information Center PDE (1973 to Present) and significant U.S. earthquake catalogs (1568-1989).

integrated between the Great Lakes and the Gulf of Mexico. Modern space geodetic measurements in North America support the predicted existence of significant glacial isostatic adjustment (GIA), particularly in the vertical. Argus et al. [1999] demonstrate that very long baseline interferometry and satellite laser ranging measurements are better fit by the VM1 model than VM2, despite the few such measurements (fewer than 10) that were then available. More recently, Park et al. [2002] compared GIA model predictions to vertical velocities from 60 continuous GPS stations in the northeastern United States to estimate best fit viscosities of $2 \times 10^{20} \mathrm{~Pa} \mathrm{~s}$ and 4.1 to $5.4 \times 10^{21} \mathrm{~Pa} \mathrm{~s}$ for the upper and lower mantle, respectively, independent of the lithospheric thickness. Both horizontal and vertical GPS velocities can thus be used to constrain GIA model parameters in North America.

[5] Finally, the existence of a link between GIA and intraplate earthquakes in North America has been hypothesized [e.g., Stein et al., 1979, 1989; Hasegawa and Basham, 1989]. Balz and Zoback [2001] proposed that the melting of the Laurentide ice sheet has resulted in stress changes sufficient to trigger increased seismicity in the New
Madrid area in the Holocene. Wu and Johnston [2000], however, found that GIA may significantly contribute to seismicity down to the Wabash Valley Seismic Zone in northern Indiana, but not in the more distant New Madrid Seismic Zone. More recently, Mazzotti et al. [2005] compared local GPS results in the St. Lawrence valley, Québec, with seismic catalog statistics and GIA models and proposed that most of the deformation related to GIA is released by large earthquakes in the Charlevoix Seismic Zone (Québec). Plate-wide GPS measurements in North America therefore have the potential to contribute to a better understanding of a possible link between GIA and seismic hazard.

[6] We present a new assessment of intraplate deformation in the North American plate interior based on data from more than 300 continuous GPS stations covering the central and eastern United States and Canada, spanning the 19932005 period (Figure 2). Our two principal emphases are to quantify deformation associated with glacial isostatic adjustment (GIA) caused by ice unloading of large areas of Canada and the northern United States at the end of the Wisconsin Ice Age, and regional strain associated with the 


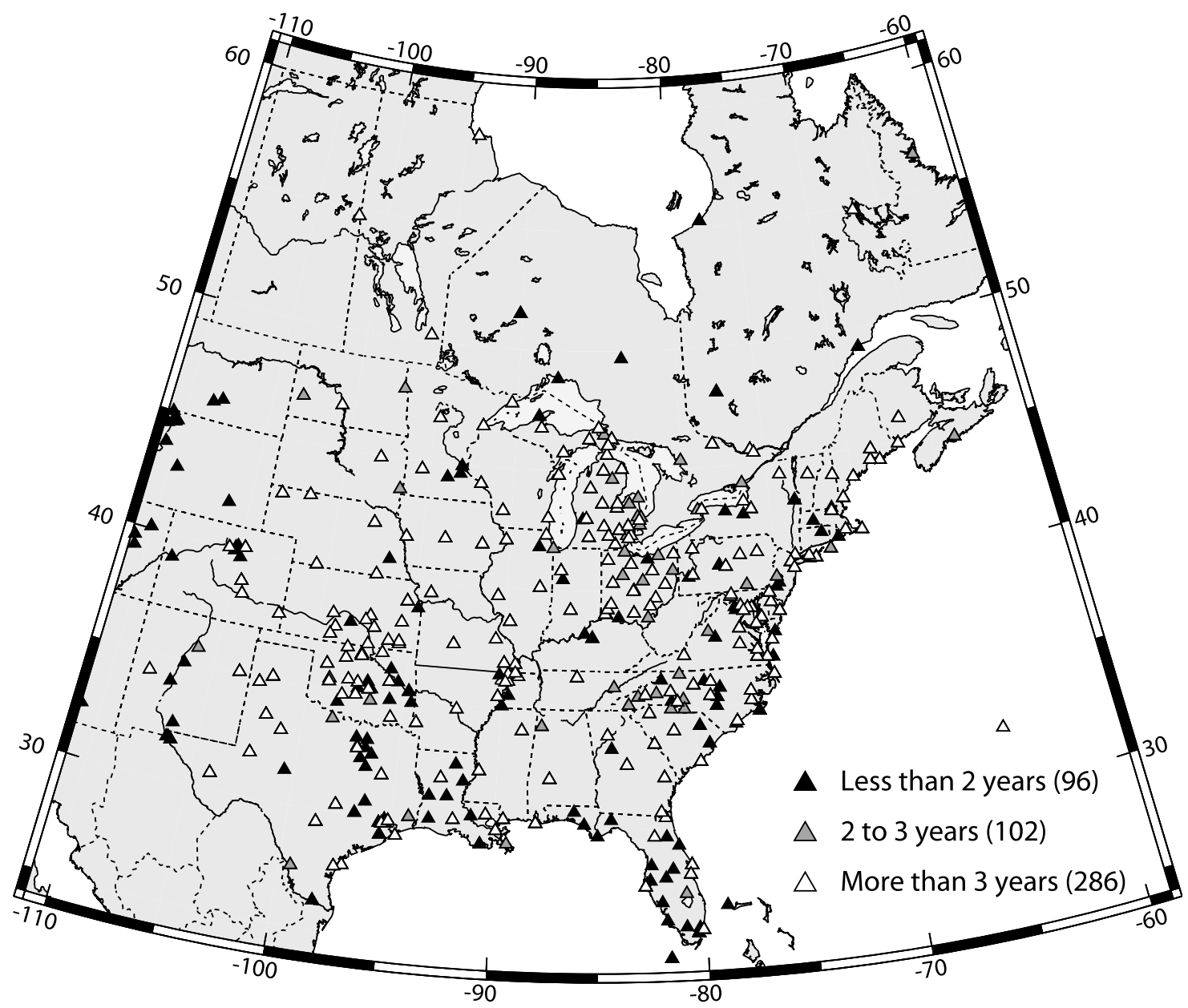

Figure 2. Map of continuous GPS stations used in this study. Symbol shadings specify length of observation time series.

New Madrid Seismic Zone. We exploit the full, plate-scale GPS velocity field to estimate rigorous upper bounds on assumed plate-scale deformation in a manner fundamentally different than prior studies, which use the weighted rootmean square misfit to their GPS velocities to estimate an upper bound on plate nonrigidity.

[7] The technical aspects of our work include three key elements: (1) the comparison and combination of independent geodetic solutions, (2) the use of as many continuous stations as possible, and (3) the use of several independent techniques for seeking significant local- to plate-scale departures from a simple rotating plate model. An important unresolved issue in determining realistic uncertainties for GPS site velocities is the degree to which nontectonic factors, some site-specific (e.g., ground contraction related to aquifer compaction, gravity-driven downslope movement, or temperature-induced monument deformation) and others regionally correlated errors (e.g., GPS orbit errors, atmospheric loading, uncorrected tidal effects) add power law noise to GPS coordinate series that cannot be fully separated from the steady tectonic site motion over short time periods [Zhang et al., 1997; Mao et al., 1999; Williams et al., 2004; Beavan, 2005]. We invest significant effort into estimating realistic uncertainties in GPS station velocities, including estimation of solution-specific uncertainties based on station-specific estimates of white and power law noise and further intercomparison of velocities from independent GAMIT and GIPSY solutions. We also assess the dependence of the magnitudes of site velocity misfit and time series noise as a function of the quality of the geodetic monumentation. To further minimize the dependence of our results and conclusions on the imperfectly known GPS velocity uncertainties, we search for geographically coherent patterns of residual site movements and use $\mathrm{F}$ ratio statistics for model comparisons, both of which are robust with respect to imperfectly known data uncertainties, provided that the uncertainties are consistently overestimated or underestimated.

\section{GPS Data and Processing}

\subsection{GPS Data}

[8] The GPS data we use are principally from the Continuously Operating Reference Station network (CORS) coordinated by the National Geodetic Survey (NGS) [Snay et al., 2002; http://www.ngs.noaa.gov/CORS/] (Figure 2). We also use data from sites that have been contributing to the International GPS Service for Geodynamics (IGS) since 1992 (in particular, continuous sites in Canada operated by the Geodetic Survey Division of Natural Resources Canada) and data from the GAMA network (operated by the Center for Earthquake Research and Information, University of 
Memphis) that covers the New Madrid Seismic Zone. Numerous monument types, many of unknown stability, are employed at CORS sites, reflecting the varying requirements of the broad CORS user community. IGS site monuments are designed for precise geodynamic applications and are presumably more stable. Most GAMA sites use $60^{\prime}$ steel $\mathrm{H}$ beams ( $10^{\prime \prime}$ flange, $10^{\prime \prime}$ web) driven to refusal into the ground, except for sites MACC and CJTR, installed on the western edge of the Mississippi embayment, that use 6-9 $\times 4^{\prime \prime}$-diameter steel pipes cemented into bedrock.

[9] Although a total of 484 sites are (or have been) operating in the study area (Figure 2), only 286 have an observation time span longer than 3 years, the minimum necessary to average out the effects of unmodeled seasonal processes such as hydrological, atmospheric loading, or tropospheric heterogeneities [Blewitt and Lavallée, 2002]. For this study, although we processed all available continuous GPS sites in the central and eastern United States and Canada, we only use sites with at least 3 years of continuous observations. Figure 3 illustrates the distribution of GPS sites in stable North America. The bulk of the sites have been operating for less than 4 years, with a sharp increase in the number of sites 3.5 years ago. This also means that in 3 years the number of CGPS sites usable for tectonic studies will have increased by about a third. As several states are currently densifying their GPS infrastructure for commercial applications, these numbers will rise even more in the near future.

\subsection{Data Processing}

[10] We have processed up to 12 years of continuous data at about 450 continuous GPS sites in the central and eastern United States and Canada. Daily data since 1 January 1993 have been processed at the University of Wisconsin using the GIPSY-OASIS software [Zumberge et al., 1997], and data since 1 January 1994 have been processed at Purdue University using the GAMIT-GLOBK software [King and Bock, 2001]. The GIPSY and GAMIT processing procedures we employ differ significantly and are described below.

\subsubsection{GIPSY-OASIS Processing}

[11] The GIPSY-OASIS solution is based on the precise point positioning analysis strategy described by Zumberge et al. [1997]. It uses free-network satellite orbits and satellite clock offsets obtained from the NASA Jet Propulsion Laboratory (JPL). Site coordinates determined from the analysis of the GPS phase and pseudorange observables are initially defined in a fiducial-free reference frame and subsequently transformed into the International Terrestrial Reference Frame 2000 (ITRF2000 [Altamimi et al., 2002]) using seven-parameter Helmert transformations that align the daily coordinates of a selected subset of ITRF2000 fiducial sites with the fiducial-free coordinates of the same subset of sites. No attempt was made to resolve integer phase ambiguities.

[12] Although the covariances for each site's daily Cartesian coordinates were calculated and propagated into estimates of each site's velocity (described below), all intersite coordinate covariances are implicitly assigned values of zero, a known shortcoming of the precise point positioning technique. For a similar point-positioned GIPSY solution, Márquez-Azúa and DeMets [2003] demonstrate

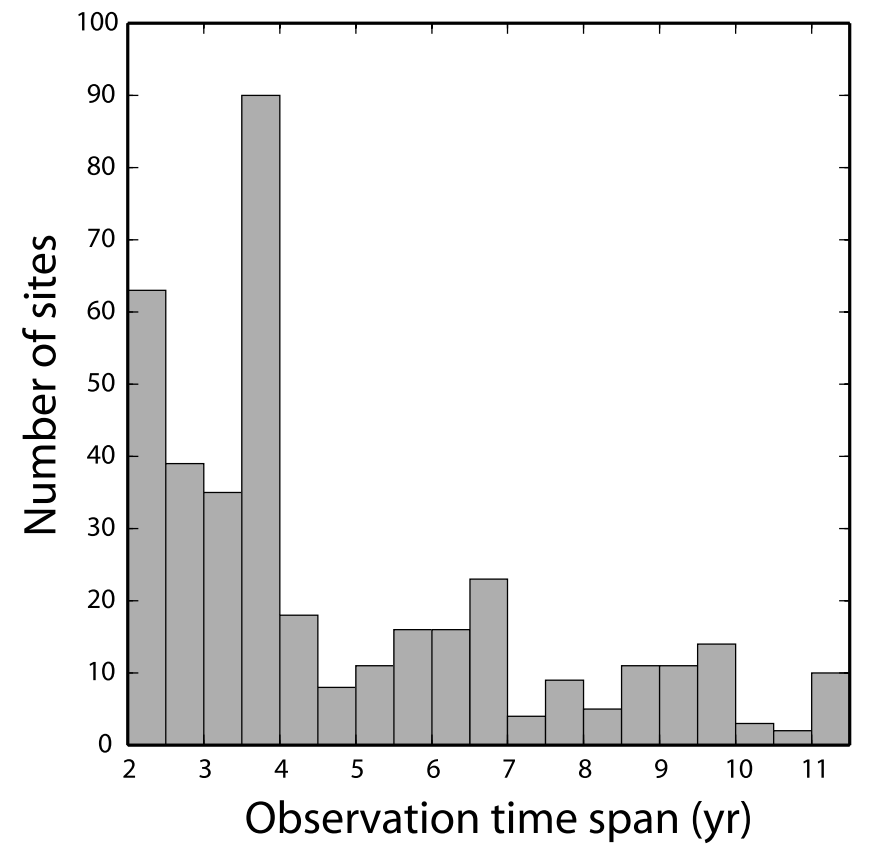

Figure 3. Distribution of measurement time spans for continuous GPS stations used in this study.

the existence of strong correlations and hence nonzero covariances between the daily coordinates of GPS stations out to interstation separations of several thousand kilometers, contrary to the assumption of zero interstation noise. They describe a time- and distance-weighted stacking algorithm that effectively estimates and removes this common mode daily and longer-period noise, thereby reducing the interstation coordinate covariances to values close to zero. We apply the same common mode error estimation correction to the present GIPSY solution.

[13] Station velocities are calculated by a linear fit to the uncorrected position time series, including estimation of antenna phase center offsets where such offsets are not specified in station site logs. Following estimation of all site velocities relative to ITRF2000, residuals for each time series are gathered and used to estimate and minimize interstation correlated noise, after which the corrected daily station positions are again regressed to estimate a refined station velocity. Typical white noise magnitudes in the north and east components are $1.5-2 \mathrm{~mm}$ and $3-3.5 \mathrm{~mm}$, respectively. Larger noise in the east component is a likely consequence of unresolved integer phase ambiguities. Station velocity uncertainties are estimated using the Mao et al. [1999] uncertainty estimation algorithm, site-specific estimates of white and flicker noise, and an assumed $1 \mathrm{~mm} \mathrm{yr}{ }^{-0.5}$ of random monument walk. Prior to its combination with other velocity solutions described below, the GIPSY velocity solution is converted into a Solution Independent Exchange (SINEX) file that contains the estimated station positions and velocities and their covariance matrix for the entire time period considered (1993.0-2005+).

\subsubsection{GAMIT-GLOBK Processing}

[14] The GAMIT-GLOBK solution uses doubledifferenced GPS phase measurements to estimate daily station coordinates, satellite state vectors, 7 tropospheric delay parameters per site and day, horizontal tropospheric 
gradients, and phase ambiguities using IGS final orbits and earth orientation parameters. We apply elevation-dependent antenna phase center models following the tables recommended by the IGS, solid Earth and polar tide corrections following the IERS standards [McCarthy, 1996], and ocean loading corrections using the CSR4.0 ocean tide mode [Eanes and Schuler, 1999] with the eight principal diurnal and semidiurnal tidal constituents. For processing time considerations, we divided the network into regional subnetworks of about 25 sites each. All subnetworks share 6 common IGS sites (AOML, USNO, ALGO, NLIB, MDO1, AMC2) well determined in ITRF2000. These sites serve to tie the subnetworks together and with the ITRF. We then produce position time series that we use to estimate sitespecific parameters for a noise model that includes white and random walk processes. We finally combine the (unconstrained) daily solutions for each subnetwork into a single, unconstrained, position velocity solution while accounting for site-specific noise parameters. That final solution is then converted into a SINEX file that contains the estimated station positions and velocities and their complete covariance matrix for the entire time period considered (1994.0-2005+).

\subsubsection{Other Solutions Used}

[15] In addition to the GAMIT and GIPSY solutions described above, we use the global solutions provided by the IGS, which results from the combination of individual solutions from IGS analysis centers, goes back to February 1999 , and include a few sites in the central and eastern United States.

[16] Finally, we use the full definition (i.e., estimates and complete covariance matrix) of the ITRF2000 [Altamimi et al., 2002]. The ITRF2000 is the current realization of the International Terrestrial Reference System (ITRS) published by the International Earth Rotation Service (IERS). Using the ITRF2000 in the combination of permanent GPS solutions ensures the consistency of the resulting solutions at a continental scale. For instance, Altamimi et al. [2002] show that global-scale GPS solutions are not consistent among themselves in the definition of the scale factor and the center of mass of the Earth. This may have a significant impact on continental-scale GPS-derived velocities, in particular for the vertical component. The ITRF2000, on the other hand, includes three very long baseline interferometry (VLBI) and seven satellite laser ranging (SLR) solutions in order to ensure the best definition of the scale factor and the Earth's center of mass, as well as their time derivatives. Consequently, using the ITRF2000 solution as a backbone for the combination of individual GPS solutions ensures the origin and scale stability of our combined solution. Finally, the ITRF2000 includes a NOAA solution for the CORS GPS network, with data until 2000.

\subsection{Combination Procedure}

[17] A key aspect of our work is the geodetic combination of independent geodetic site coordinate and velocity solutions. Rigorous combination of alternative geodetic solutions offers a number of important advantages over using a single velocity solution, including averaging down of random and any systematic errors associated with individual processing strategies, outlier detection via cross-checking of the independent solutions, definition of a single consistent reference frame for the combined solutions, and realistic estimates of the velocity uncertainties.

[18] We use the combination algorithm developed by Altamimi et al. [2002], also used to calculate ITRF2000, starting with minimally constrained geodetic solutions. The combination consists of simultaneously estimating, for each site $i$ in solution $s$ ( $s=$ GAMIT, GIPSY, IGS, ITRF2000), the position $X_{\text {comb }}^{i}$, the velocity $\dot{X}_{\text {comb }}^{i}$, and a 14-parameter transformation between the individual and the combined solution using

$$
\begin{aligned}
& X_{s}^{i}=X_{\text {comb }}^{i}+\left(t_{s}-t_{0}\right) \dot{X}_{\text {comb }}^{i}+T_{k}+D_{k} X_{\text {comb }}^{i}+R_{k} X_{\text {comb }}^{i} \\
& +\left(t_{s}-t_{k}\right)\left[\dot{T}_{k}+\dot{D}_{k} X_{\text {comb }}^{i}+\dot{R}_{k} X_{\text {comb }}^{i}\right] \\
& \dot{X}_{s}^{i}=\dot{X}_{\text {comb }}^{i}+\dot{T}_{k}+\dot{D}_{k} X_{\text {comb }}^{i}+\dot{R}_{k} X_{\text {comb }}^{i}
\end{aligned}
$$

where $X_{s}^{i}$ is the position of site $i$ in solution $s$ at epoch $t_{s}$, $X_{\text {comb }}^{i}$ the estimated position of site $i$ at epoch $t_{0}$, and $\dot{X}_{\text {comb }}^{i}$ its final velocity in the combination, $T_{k}, D_{k}, R_{k}$ and $\dot{T}_{k}, \dot{D}_{k}, \dot{R}_{k}$ are the transformation parameters between individual solutions $s$ and the combined solution and their time derivatives, $t_{s}$ is the epoch of minimal position variance for the solution $s$, which is generally the middle point of the observation time span included in the solution, and $t_{k}$ is the epoch of expression of the transformation parameters.

[19] The reference frame definition in the combination is implemented by imposing the 14-parameter transformation between ITRF2000 and the combined solution to be zero (no translation, scale factor, or rotation and no rate of change of these parameters). The resulting velocity field is therefore expressed in ITRF2000.

[20] From the preliminary combination, an a posteriori variance factor $\sigma_{s}^{2}$ is estimated for each individual solution $s$ in the inversion, at the same time as the other parameters. This variance factor is then applied to the covariance matrix of the corresponding individual solution in an iterative way until both individual $\sigma_{s}^{2}$ and the global a posteriori variance factor equal unity. As a result of this iterative scaling, formal errors of the combined solution depend on the variance of the individual solutions before the combination, but also on the level of agreement between solutions in the combination.

\subsection{Statistics of the Combination}

[21] The result of the combination is a SINEX file in which positions and velocities are expressed in ITRF2000. We obtain variance scaling factors ranging from 0.7 to 12.2 (Table 1), consistent with empirical scaling factors derived from time series analysis [Zhang et al., 1997; Mao et al., 1999; Williams, 2003]. The GIPSY solution has a lower variance factor because velocity uncertainties were estimated with a model that includes white, flicker, and random walk noise. The level of agreement between solutions and the combination, given by the weighted RMS (WRMS) shown in Table 1 , is on the order of $0.5 \mathrm{~mm} \mathrm{yr}^{-1}$ or better for the horizontal components.

[22] Two of the solutions included in the combination (GAMIT and GIPSY solutions) account for colored noise in the velocity error estimates. In addition, the iterative variance scaling scheme used here results in velocity uncertainties in 
Table 1. Statistics of the Combination

\begin{tabular}{|c|c|c|c|c|c|}
\hline \multirow[b]{2}{*}{ Solution } & \multirow{2}{*}{$\begin{array}{c}\text { A Posteriori } \\
\text { Variance Factor }\end{array}$} & \multicolumn{2}{|c|}{$\begin{array}{c}\text { Position } \\
\text { WRMS, mm }\end{array}$} & \multicolumn{2}{|c|}{$\begin{array}{c}\text { Velocity } \\
\text { WRMS, mm/yr }\end{array}$} \\
\hline & & Horizontal & Vertical & Horizontal & Vertica \\
\hline GAMIT & 2.4 & 0.8 & 5.2 & 0.5 & 2.0 \\
\hline GIPSY & 0.7 & 1.8 & 1.3 & 0.2 & 0.5 \\
\hline IGS & 12.2 & 1.8 & 5.9 & 0.5 & 1.1 \\
\hline ITRF & 2.8 & 0.7 & 3.5 & 0.4 & 0.7 \\
\hline
\end{tabular}

the combination that are larger than in the individual solutions (except for the GIPSY solution, as mentioned above). The final uncertainties of the combined solution may thus be somewhat conservative.

[23] Figure 4 shows that velocity uncertainties decrease rapidly during the first 2.5 to 3 years of continuous measurements, consistent with predictions by Blewitt and Lavallée [2002]. Velocity uncertainties decrease more slowly thereafter, reflecting the longer periods that are required to average down the flicker and random walk noise that affects GPS monument motions. The best determined site velocities $(\sim 11$ years of continuous data) have respective horizontal and vertical standard deviations of about $\pm 0.2 \mathrm{~mm} \mathrm{yr}^{-1}$ and $\pm 0.6 \mathrm{~mm} \mathrm{yr}^{-1}$.

[24] One useful outcome of our analysis is a comparison of the individual GAMIT and GIPSY solutions for a large number of sites and over a long time period. Applying procedures outlined in section 2.3, we estimated and applied a 14-parameter Helmert transformation between the individual GIPSY and GAMIT solutions and the IGS combined solution using 28 common IGS sites. We then subtracted velocities predicted by the best fitting North AmericaITRF2000 angular velocity vector described below from the resulting GAMIT and GIPSY velocity fields and compared residual velocities at the sites common to the two solutions (Figure 5). We find that the horizontal components of the GAMIT and GIPSY velocities agree within 0.6-

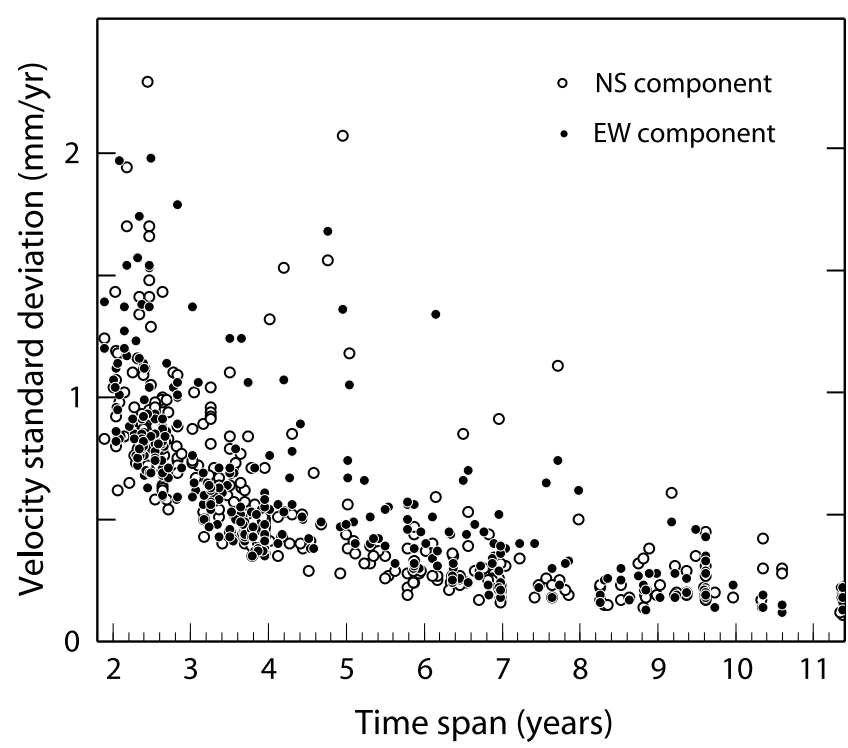

Figure 4. Velocity standard deviation as a function of measurement time span.
$0.8 \mathrm{~mm} \mathrm{yr}^{-1}$ on average, with a negligible bias $(0.3$ and $-0.1 \mathrm{~mm} \mathrm{yr}^{-1}$ for the E-W and N-S components, respectively). Differences in the vertical component are larger, typically within $3 \mathrm{~mm} \mathrm{yr}^{-1}$ of their mean value.

\section{Analysis of the Velocity Field}

[25] The resulting velocity field describes surface motions with respect to ITRF2000 (Figure 6, top), illustrating the well-known counterclockwise rotation of the North American plate in a no-net-rotation frame. We next use the new velocity field to define North American plate motion and use residual velocities with respect to the new best fitting

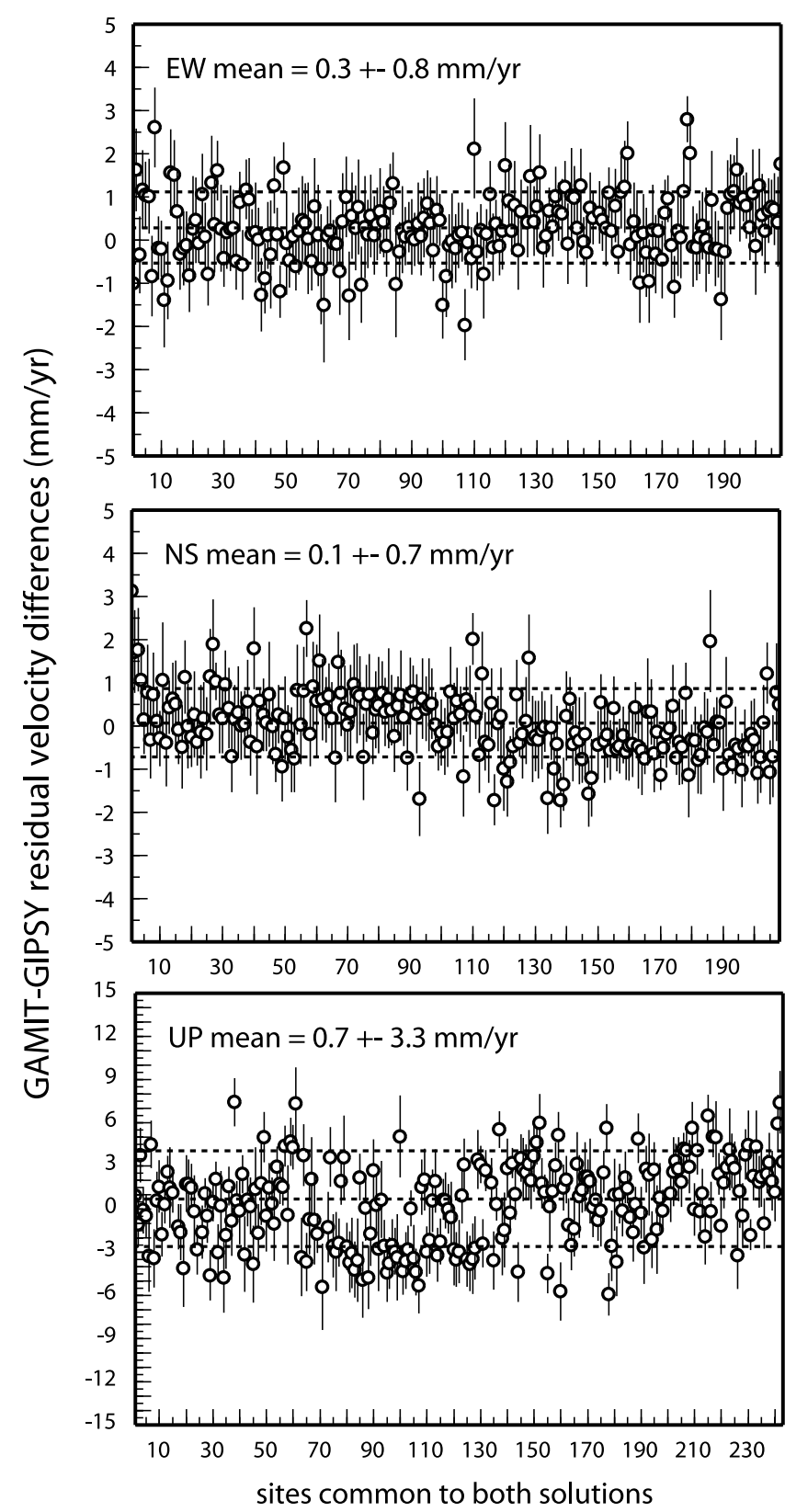

Figure 5. Comparison of GAMIT and GIPSY GPS site velocities. Dotted lines show the mean difference and its \pm 1 standard deviation. 

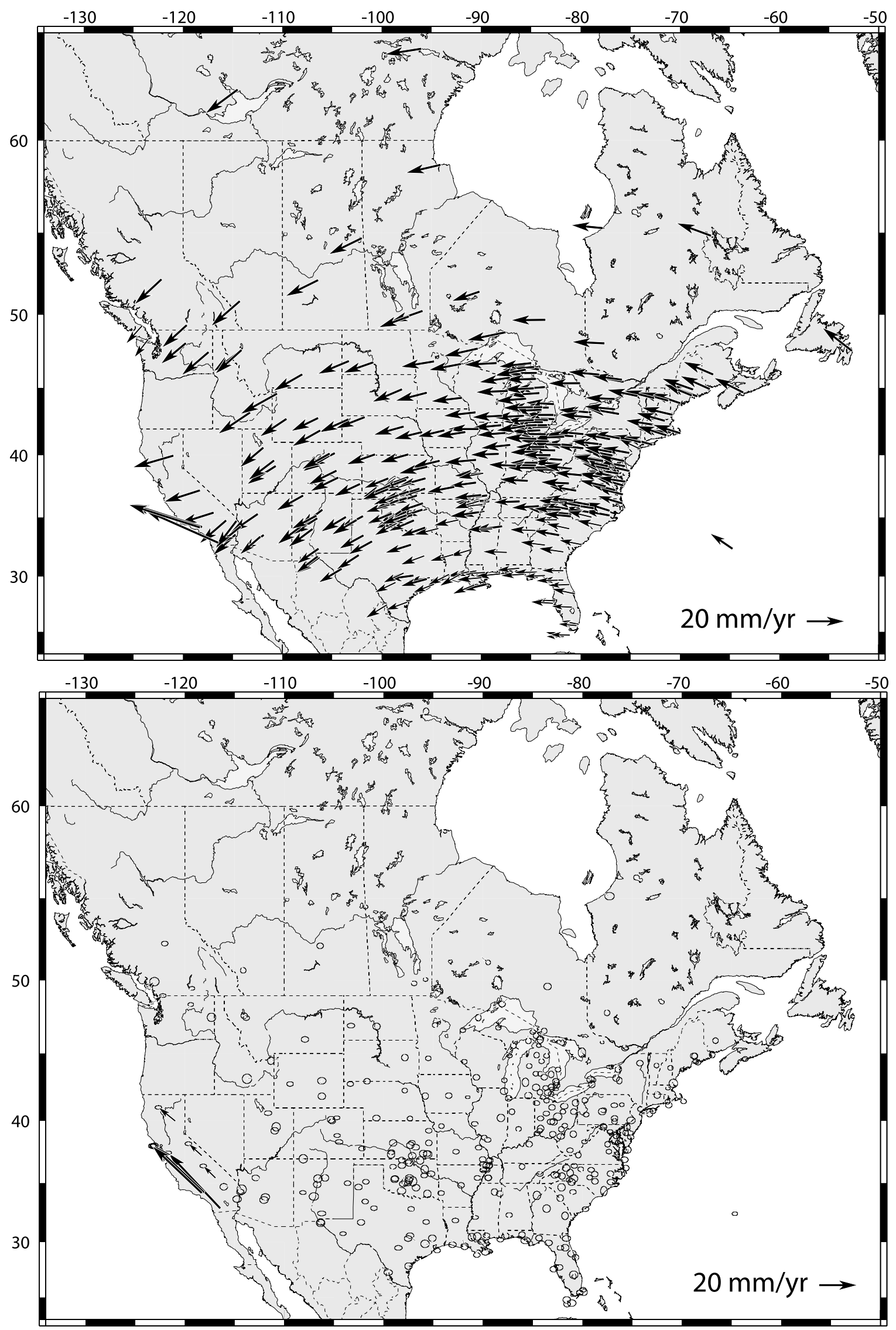

Figure 6. (top) GPS-derived station velocities in ITRF2000. (bottom) Residual velocities with respect to North America. 
reference frame to describe areas of the plate where significant deformation appears to be occurring.

\subsection{Defining Rigid North America}

[26] Efforts to detect and model strain anomalies in the North American plate interior that are caused by tectonic processes, glacial isostatic adjustment (GIA), or possibly groundwater withdrawal require a well-determined plate reference frame. A purely kinematic end-member approach for defining such a frame is to exclude a priori all sites in geographic areas where deformation could occur. Alternatively, one can assimilate the entire GPS velocity field into deformation models while solving for the rotation, translation, and possibly scale factor that define the frame (e.g., G. Blewitt et al., A Stable North American Reference Frame (SNARF): First release, 2005, available at http://www.unavco.org/research_science/workinggroups_projects/snarf/ SNARF1.0/SNARF1.0.html, hereinafter referred to as Blewitt et al., unpublished report, 2005). The former approach avoids the need for modeling assumptions beyond that of the rigid plate assumption, but decreases the number and geographic expanse of sites that are used to define the frame and thus reduces the potential accuracy and precision of the plate angular velocity vector. The latter approach makes use of the full spatial coverage of the velocity field, but introduces modeling tradeoffs between the plate angular velocity vector and the parameters used to describe the a priori physical model.

[27] For the analysis below, we use the former, purely kinematic, approach. We use only the velocities of GPS sites located east of $110^{\circ} \mathrm{W}$, thereby avoiding potential contamination of the velocity field by possible slow deformation west of the Rio Grande rift and central Colorado. For sites east of $110^{\circ} \mathrm{W}$, we treat the area where the plate interior is potentially affected by distributed deformation as an unknown and use the F statistic introduced by Stein and Gordon [1984] to identify the approximate geographic limits of areas affected by GIA. Although the Stein and Gordon [1984] F test is designed to detect narrow or wide plate boundaries between rigid, independently moving plates, it can also be applied to detection of GIA at sites in southern Canada and the northern United States, where the GIA response is generally to the south and is sufficiently uniform in magnitude $\left(1 \pm 1 \mathrm{~mm} \mathrm{yr}^{-1}\right)$ such that it can be well approximated by a slow counterclockwise rotation about a pole that is suitably located to predict southward motion in Canada. The net velocity field of sites in areas affected by GIA is thus well approximated by a single angular velocity vector that is the sum of the North American plate angular velocity (relative to ITRF2000) and the angular velocity that approximates the GIA response.

[28] To implement the test, we divided the GPS station velocities into two subnetworks, one consisting of sites that are located farther than some specified distance from the approximate center of GIA uplift in North America and the other consisting of sites within the specified distance. The distance is treated as an adjustable parameter. The locus of maximum uplift (called "GIA center" below) is still poorly constrained, so we approximated it using the location determined from the assimilation of GPS data into GIA models by Blewitt et al. (unpublished report, 2005,

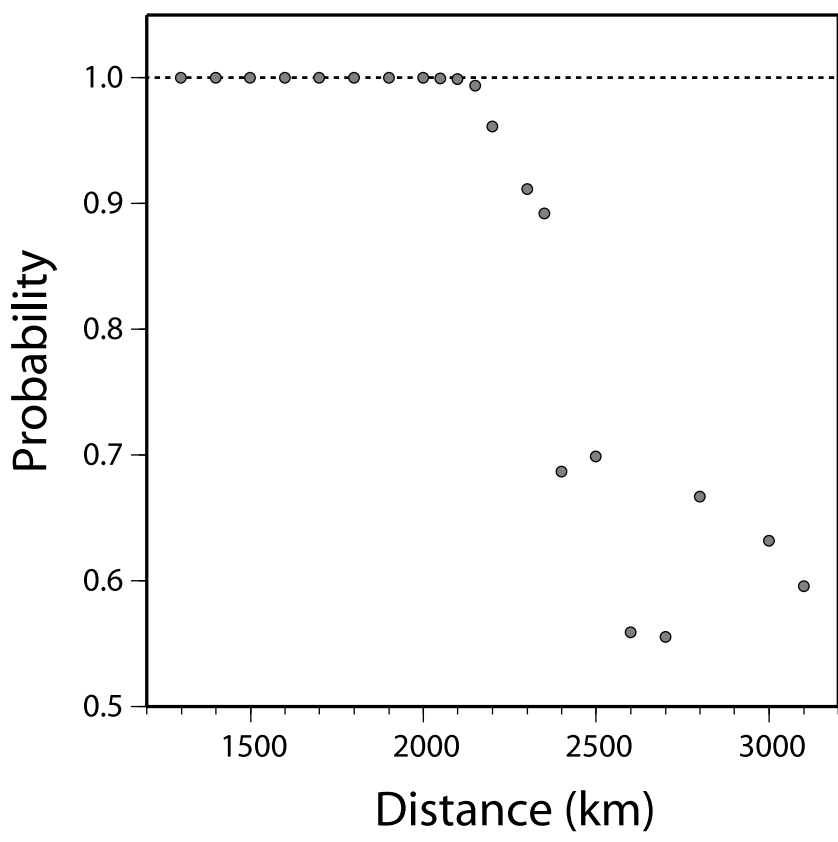

Figure 7. Improvement in fit to horizontal GPS velocities from the North American plate interior of a two subnetwork model relative to a single network model as a function of distance to the center of the GIA uplift. The probability of the observed improvement in the least squares fits of the two network model is determined using an F ratio test for 3 versus $2 N-3$ degrees of freedom, where $N$ is the number of GPS sites (267) used for the comparison.

Stable North America Reference Frame, $55^{\circ} \mathrm{N}-75^{\circ} \mathrm{W}$ ). Velocities from both subnetworks are fit via a joint estimation of separate angular velocity vectors for the two subnetworks. The least squares fit for the two subnetwork model is compared to the least squares fit of a single angular velocity for the entire data set as follows:

$$
F=\frac{\left(\chi_{3}^{2}-\chi_{6}^{2}\right) /(6-3)}{\chi_{6}^{2} /(2 N-6)}
$$

where $N$ is the number of GPS sites used in the estimation and $\chi_{3}^{2}$ and $\chi_{6}^{2}$ are the $\chi^{2}$ values for the one network and two network models, respectively. The significance level for the observed $F$ value is compared to that expected for $F(3$, $2 N-6)$.

[29] Figure 7 shows the probability of the observed improvement in fit calculated from (3) as a function of distance from the assumed center of GIA uplift. The twosubnetwork model improves the fit at the $99 \%$ confidence level or better for all subnetwork geometries with a shared border that lies within $2100 \mathrm{~km}$ of the assumed GIA uplift maximum. Given that the sites we employ are dominantly located south of Hudson Bay (Figure 2), the $2100 \mathrm{~km}$ cutoff between areas that are and are not affected by GIA is largely derived from the numerous velocities in the central and eastern United States. This cutoff thus does not apply to areas east, west, or north of Hudson Bay, where too few site velocities are found for a meaningful GIA analysis. In sections 3.2-3.4, we use two techniques to demonstrate 


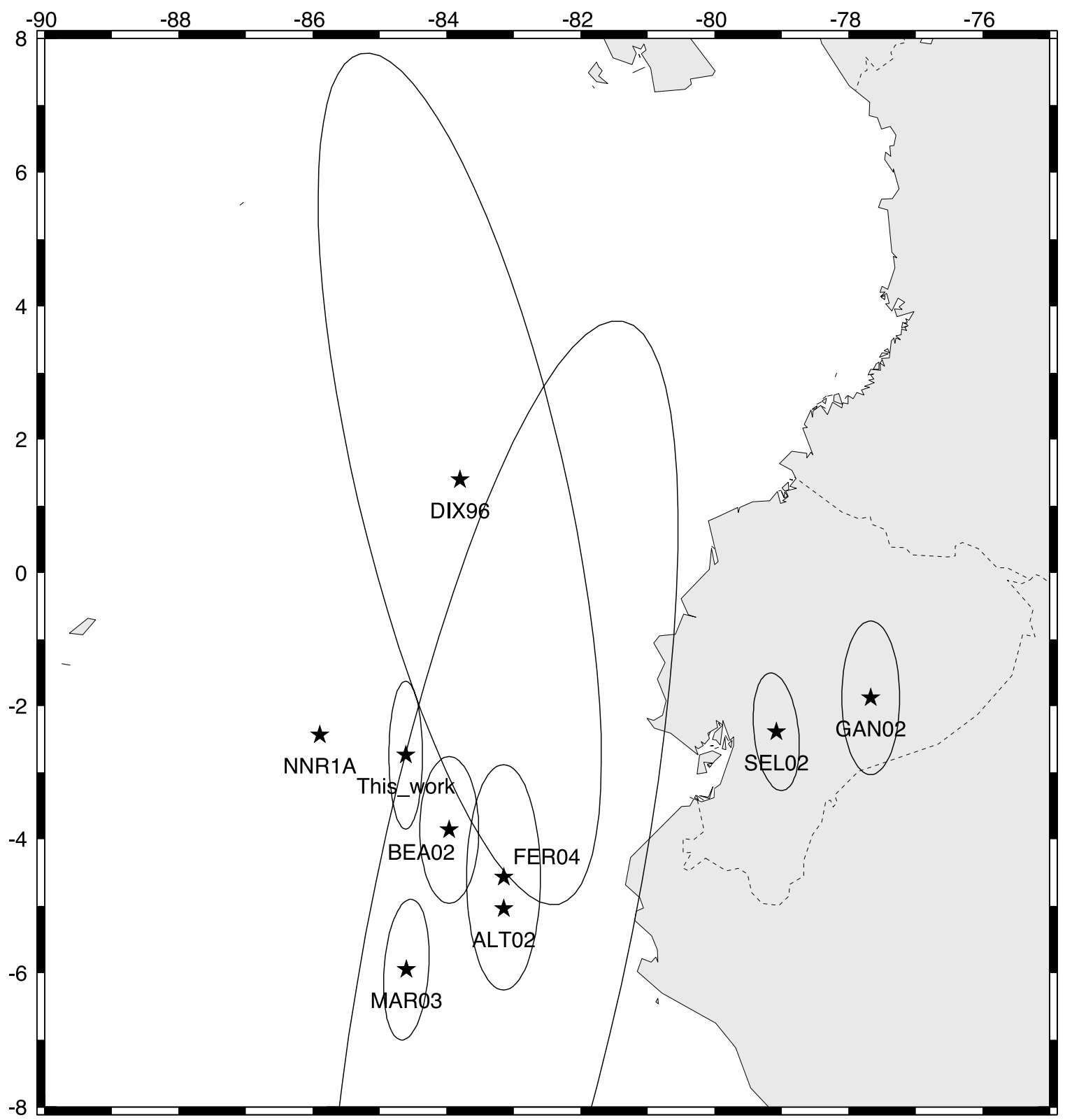

Figure 8. Location of the North America/ITRF2000 rotation pole (ALT02, Altamimi et al. [2002]; NNR1A, DeMets et al. [1994]; SEL02, Sella et al. [2002]; DIX96, Dixon et al. [1996]; GAN02, Gan and Prescott [2001]; MAR02, Márquez-Azúa and DeMets [2003]; BEA02, Beavan et al. [2002]; FER04, Fernandes et al. [2004]).

the existence and character of the strain gradient associated with GIA at latitudes south of Hudson Bay. Both strongly support the transition to measurable amounts of deformation associated with GIA at distances within $2100-2200 \mathrm{~km}$ from the uplift maximum.

[30] On the basis of the above results, we calculate the North American plate angular velocity with respect to ITRF2000 using sites located at least $2100 \mathrm{~km}$ away from the GIA center of uplift. Using all the available sites (208 total) yields a reduced $\chi^{2}$ of 1.7 , with a WRMS of $0.9 \mathrm{~mm} \mathrm{yr}^{-1}$ for both the east and north components. Our best fitting NOAM/ITRF2000 angular velocity $\left(2.7^{\circ} \mathrm{S} \pm\right.$ $0.6^{\circ}, 84.6^{\circ} \mathrm{W} \pm 0.2^{\circ}, 0.202 \pm 0.002^{\circ} / \mathrm{Myr} ; 0.202 \pm 0.002^{\circ} \%$ Myr; Figure 8) is close to recent values from Altamimi et al.
[2002], Beavan et al. [2002], Márquez-Azúa and DeMets [2003], and Fernandes et al. [2004].

[31] We inverted subsets of the site velocities with successively smaller standard errors (reflecting sites with longer and thus presumably better determined velocities). The resulting best fitting angular velocities do not change significantly, with predicted station velocities in the plate interior that differ by less than $0.2 \mathrm{~mm} \mathrm{yr}^{-1}$. The entire set of sites located east of $110^{\circ} \mathrm{W}$ and more than $2100 \mathrm{~km}$ from the GIA uplift center is thus consistent with the best fitting angular velocity, including sites with the shortest time series and hence largest uncertainties. For the 119 sites with the best determined velocities, corresponding to those with velocity standard deviations smaller than $1 \mathrm{~mm} \mathrm{yr}^{-1}$, the 
WRMS of the residual velocities is $0.7 \mathrm{~mm} \mathrm{yr}^{-1}$ for the horizontal components.

\subsection{Monument Stability}

[32] Monument stability is a significant issue in the study area because most of the GPS antenna mounts were not designed for tectonic applications. Antennas are mounted on features that range from concrete pillars to fence posts. NGS recently collected information on geodetic monuments at all the CORS sites (G. Sella, personal communication, 2005). On that basis, we divided the sites in two categories. Category A sites, the monuments that are the most suitable for tectonic applications, consist of monuments installed in bedrock, braced monuments, anchored pillars, or metal rods driven to refusal. Category B sites consist of rooftop monuments and ground monuments that do not belong in category A such as fence posts, unbraced monuments, masts, and towers.

[33] We assessed monument stability as a function of monument type using two independent measures of monument stability, namely, the magnitude of the random walk noise present in the detrended individual station coordinate time series [Langbein and Johnson, 1997] and the magnitude of the residual site velocities relative to the best fitting model predictions (assuming a single rigid plate rotation). The former provides useful information about long-term monument stability and the relative stabilities of differing monument types, independent of plate modeling assumptions. Use of the residual site motions to study monument stability requires an assumption that no internal plate deformation occurs. If empirically based algorithms for estimating site velocity uncertainties are approximately correct, then a regression of site velocity misfits versus estimated velocity uncertainties should yield a slope of one and intercept of zero. Departures from those values may yield useful insights about the existence of systematic errors in site velocities that are not captured through time series analysis and thus are not incorporated into empirical algorithms for estimating velocity uncertainties.

[34] Random walk noise was estimated for each site time series using the maximum likelihood estimator (MLE) technique described by Langbein and Johnson [1997]. Random walk noise magnitudes are less than $2 \mathrm{~mm} / \mathrm{yr}^{1 / 2}$ (Figure $9 \mathrm{a}$ ) at more than $90 \%$ of category A sites, and never exceed $3 \mathrm{~mm} / \mathrm{yr}^{1 / 2}$. In contrast, $\sim 30 \%$ of the category B sites exhibit random walk noise magnitudes greater than 2 $\mathrm{mm} / \mathrm{yr}^{1 / 2}$ (Figure $9 \mathrm{a}$ ), with $\sim 10 \%$ of the sites exhibiting values greater than $5 \mathrm{~mm} \mathrm{yr}^{-1 / 2}$. Category A sites are also more likely to have smaller residual velocities than are category B sites (Figure $9 b$ ), with $\sim 75 \%$ of category A sites exhibiting residual velocities smaller than $1.2 \mathrm{~mm} \mathrm{yr}^{-1}$ versus $\sim 60 \%$ of category B sites.

[35] Despite evidence that category A sites are more likely to have smaller random walk noise and residual velocities than are category B sites, no clear correlation emerges between the magnitude of random walk noise for an individual site and the magnitude of its residual velocity (Figure 10). Although this might imply that systematic sources of noise in monument motion are more important than is random monument wander in causing deviations from rigid plate behavior at individual sites, we instead suspect that the expected correlation will emerge once the
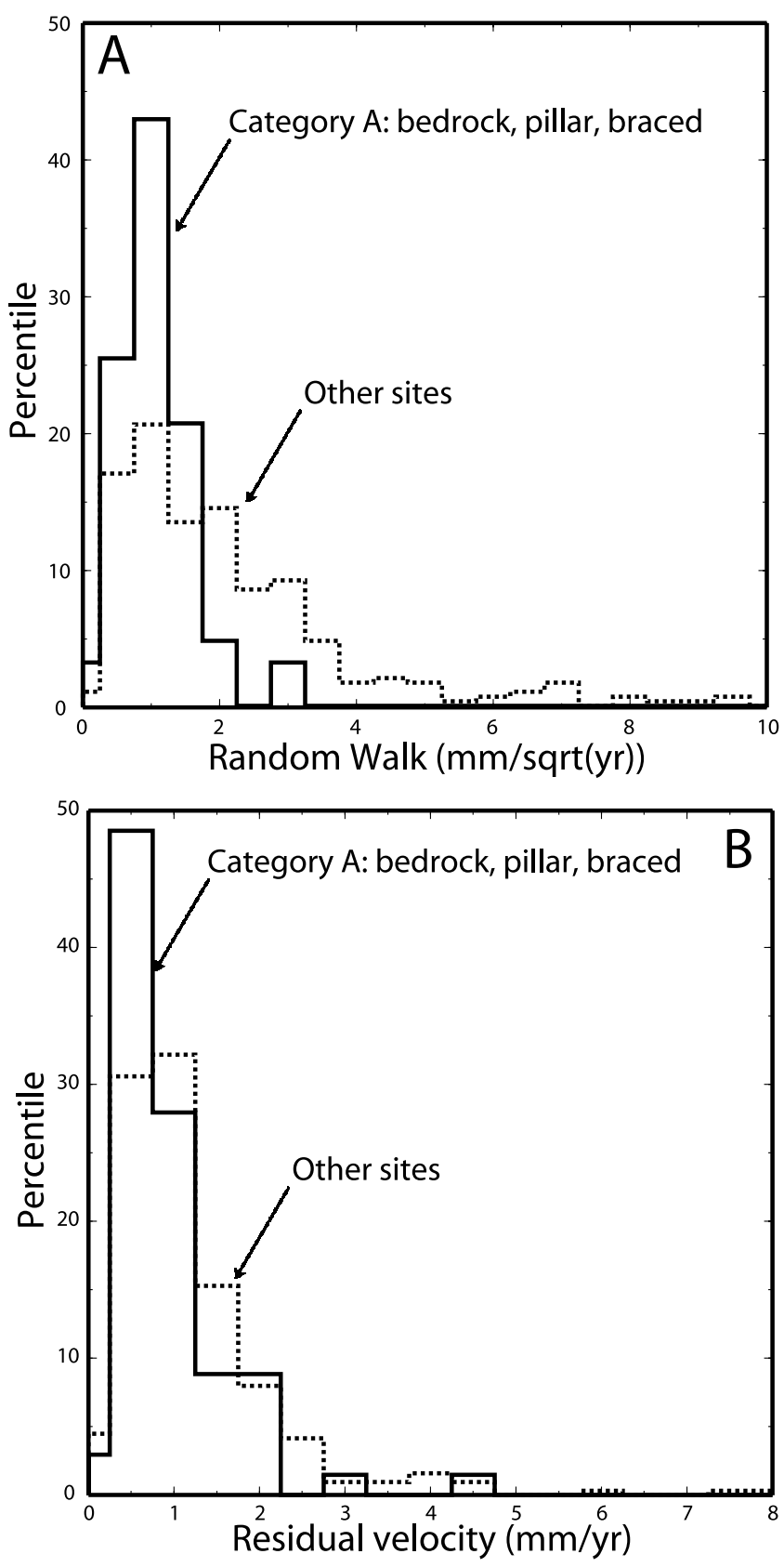

Figure 9. (a) Site distribution as a function of random walk noise magnitude for category A sites (solid line) and other sites (dashed line). (b) Distribution of residual velocities for category A sites (solid line) and other (dashed line).

measurement time spans at most sites get significantly longer than 5 years, the minimum required in order to reliably estimate random walk noise parameters [Langbein and Johnson, 1997].

[36] If no deformation occurs in a plate interior and monument motion does not include systematic components, which do not average down over time, residual site velocities should decrease as measurement time spans increase due to averaging down of long-period noise. Surprisingly, we find no clear correlation between the misfit magnitudes and observation time spans (Figure 11a), nor do we find a 


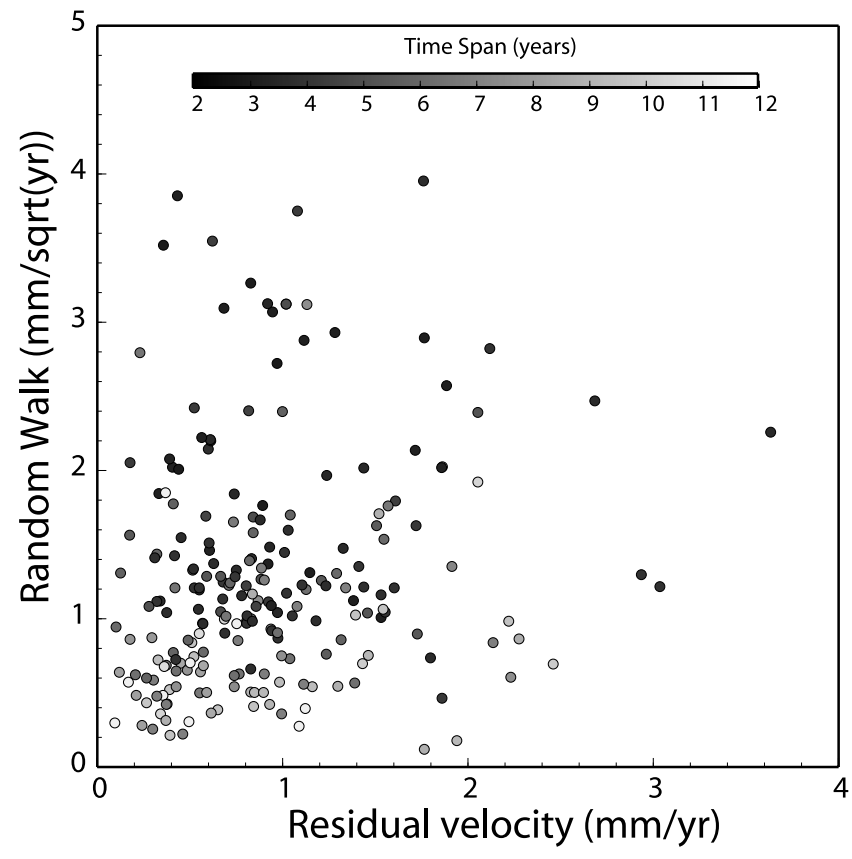

Figure 10. Residual velocities as a function of random walk noise.

compelling correlation between the misfit magnitudes and velocity uncertainties (Figure 11b). Large velocity misfits $\left(>2 \mathrm{~mm} \mathrm{yr}^{-1}\right)$ are found at sites with small velocity uncertainties and long observation spans, even for sites with presumably more stable monumentation.

[37] The lack of evidence for obvious correlations between measurement time span, velocity misfits, and monument quality as measured by monument type and the magnitude of random monument wander is an unexpected outcome of our analysis. One possible explanation for this result is that deviations from the idealized rigid plate motion at a given site may be strongly influenced by systematic noise or noise that occurs at decadal or longer scales, too long to be fully characterized with the present GPS time series. Such noise could arise from geologic or hydrologic processes, could result from long-term site-specific changes in antenna multipath noise, or could be an artifact introduced by one or both of our data processing schemes.

\subsection{Residual Velocities}

[38] Residual velocities with respect to stable North America as defined above are not significant at most sites at the $95 \%$ confidence level (Figure 12). They appear to be randomly distributed in direction and magnitude south of about $38^{\circ} \mathrm{N}$. North of that latitude, however, latitude, however, we observe systematic residual site motions of $0.5-2 \mathrm{~mm} \mathrm{yr}^{-1}$ toward the south and southeast, particularly at sites in Canada southwest of Hudson Bay and sites in the Great Lakes area, upper Midwest, and New England (Figure 13).

[39] Evidence for the south to southeastward bias in velocities in these areas is also illustrated by the distribution of residual velocities shown in Figure 14. For the entire study area as well as for sites located more than $2100 \mathrm{~km}$ from the GIA center, the residual velocities define a Gaussian distribution centered on a zero-mean residual velocity. Residual velocities at sites located within
$2100 \mathrm{~km}$ of the GIA center, however, show a deviation from a zero-mean for the north component, consistent with results reported in section 3.1.

[40] We next use three different techniques to seek spatially coherent patterns within the residual velocities and establish rigorous limits on their geographic extent and strain rates. Previous authors have used the weighted root-mean square misfit of the angular velocity vector that
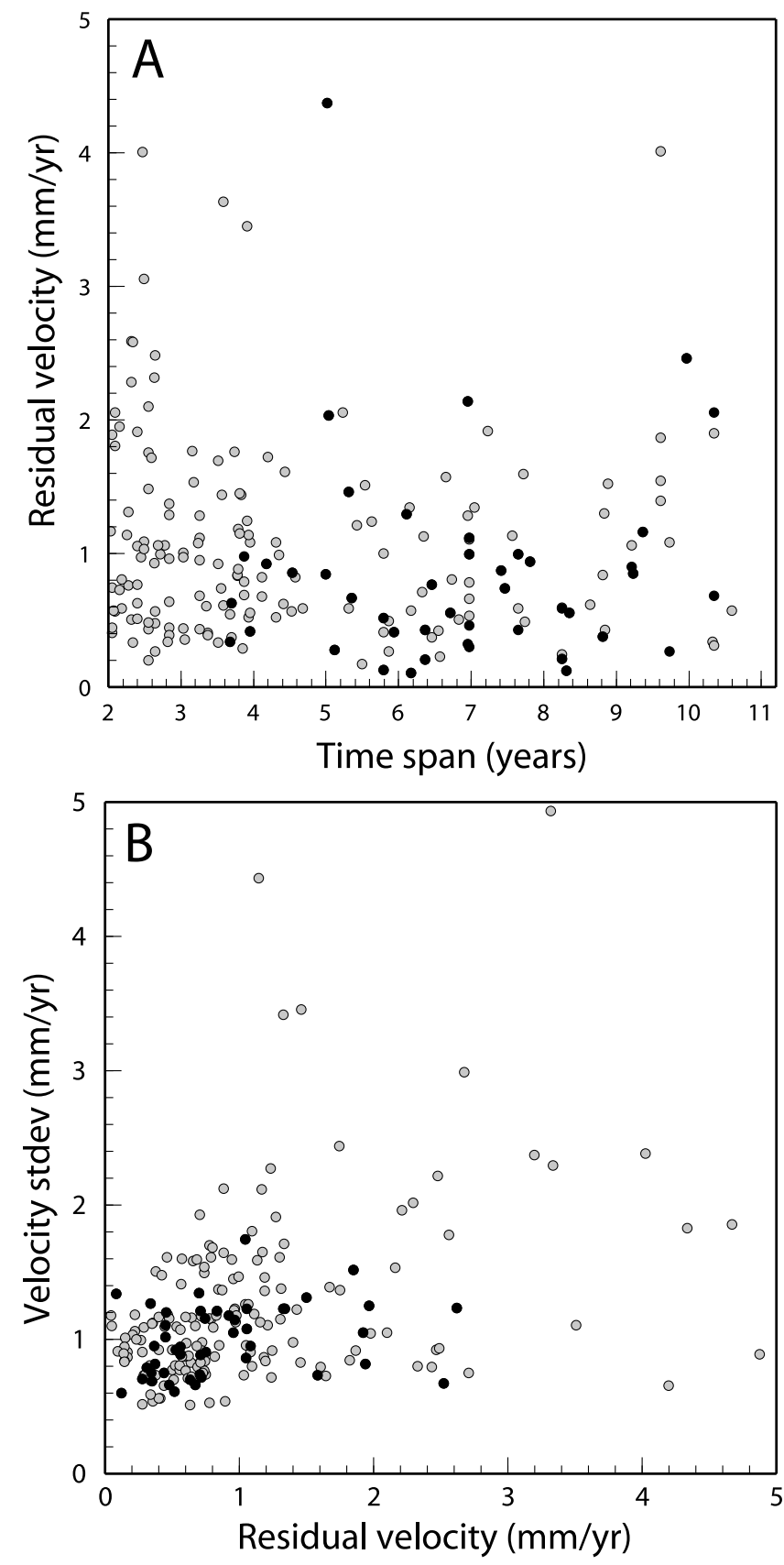

Figure 11. (a) Residual velocities as a function of observation time span. Black circles are sites with random walk noise magnitude smaller than $1 \mathrm{~mm} \mathrm{yr}^{-1 / 2}$ and category A sites. (b) Residual velocities as a function of velocity standard deviation. Black circles are sites with random walk noise magnitude smaller than $1 \mathrm{~mm} \mathrm{yr}^{-1 / 2}$ and category A sites. 


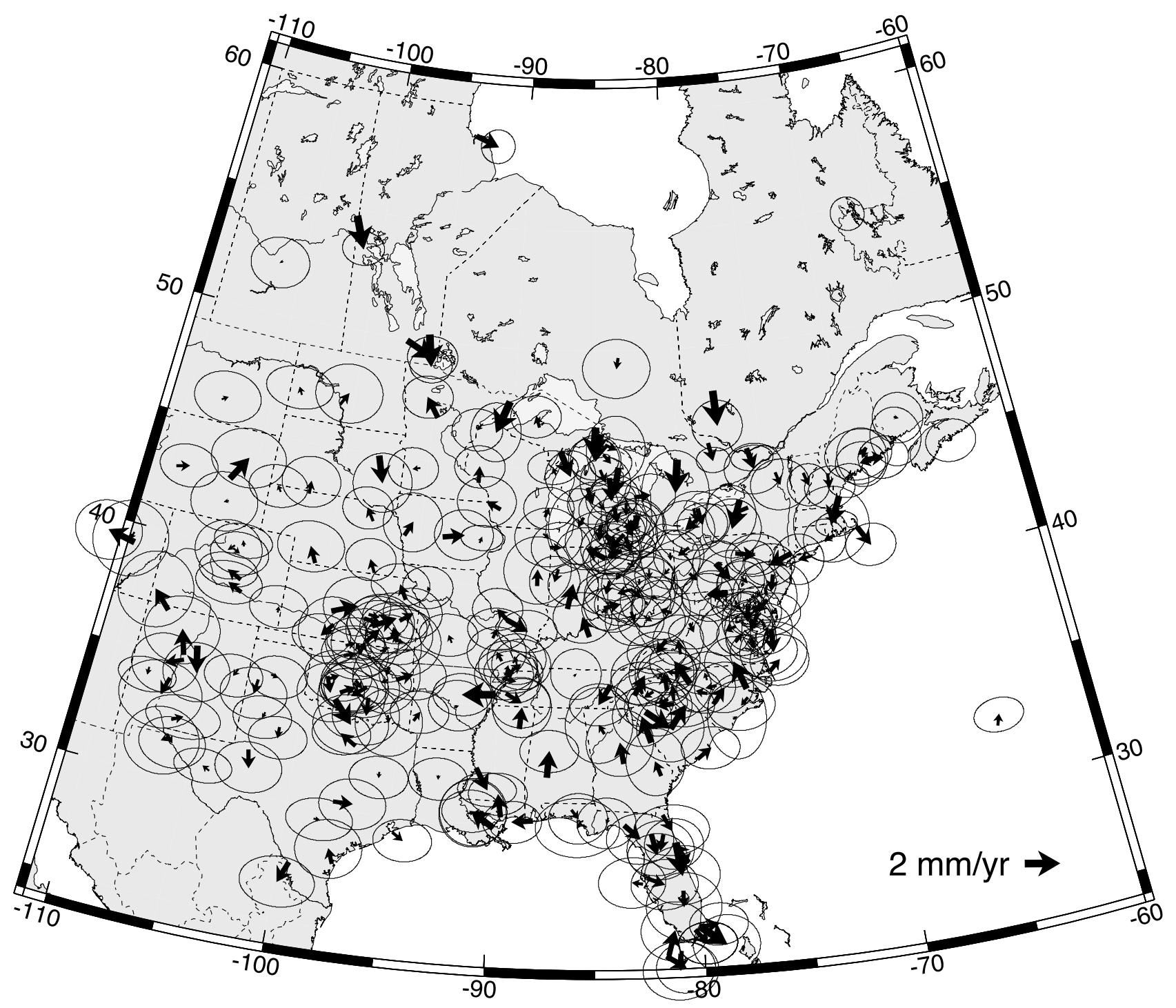

Figure 12. Residual velocities after removal of the best fit NOAM/ITRF2000 angular velocity. Only sites with velocity standard deviation less than $1 \mathrm{~mm} / \mathrm{yr}$ and velocity magnitude less than $2.0 \mathrm{~mm} \mathrm{yr}^{-1}$ are shown here. Ellipses are 95\% confidence.

best fits their respective North American plate GPS velocity fields to estimate an upper limit for internal plate deformation [e.g., Argus and Gordon, 1996; Dixon et al., 1996; Márquez-Azúa and DeMets, 2003], yielding a 95\% upper limit of $\sim 2 \mathrm{~mm} \mathrm{yr}^{-1}$ on intraplate deformation. Because such estimates reflect the random dispersion of the station velocities with respect to the model predictions, they are of little use for detecting and characterizing the magnitude of any distributed plate deformation, which is likely to be spatially coherent. In contrast, the techniques we employ are designed to extract spatially coherent patterns.

\subsection{Spatial Filtering}

[41] If the residual site velocity vectors for locations farther than $2100 \mathrm{~km}$ from the GIA center are truly random, then averaging the residual velocities over geographic areas of appropriate size should reduce the averages to values close to zero. Conversely, any regionally coherent patterns in residual velocities should be enhanced via spatial aver- aging of residual velocities, provided that averaging occurs over appropriately sized geographic areas. We therefore take advantage of the spatial redundancy in the GPS station velocities by computing regional averages $v$ using

$$
v=\frac{\sum_{i=1}^{N} w_{i} v i}{\sum_{i=1}^{N} w_{i}}
$$

where $v_{i}$ are measured GPS velocities and $w_{i}$ a weighting function based on an nearest neighbor search scheme defined by:

$$
w_{i}=\frac{1}{\sigma_{i}^{2}} \times \frac{1}{1+\frac{(3 d)^{2}}{d_{S}^{2}}}
$$

$\sigma_{i}$ is the standard deviation of the GPS velocities, $d$ the distance between GPS sites, and $d_{S}$ a given search radius. 


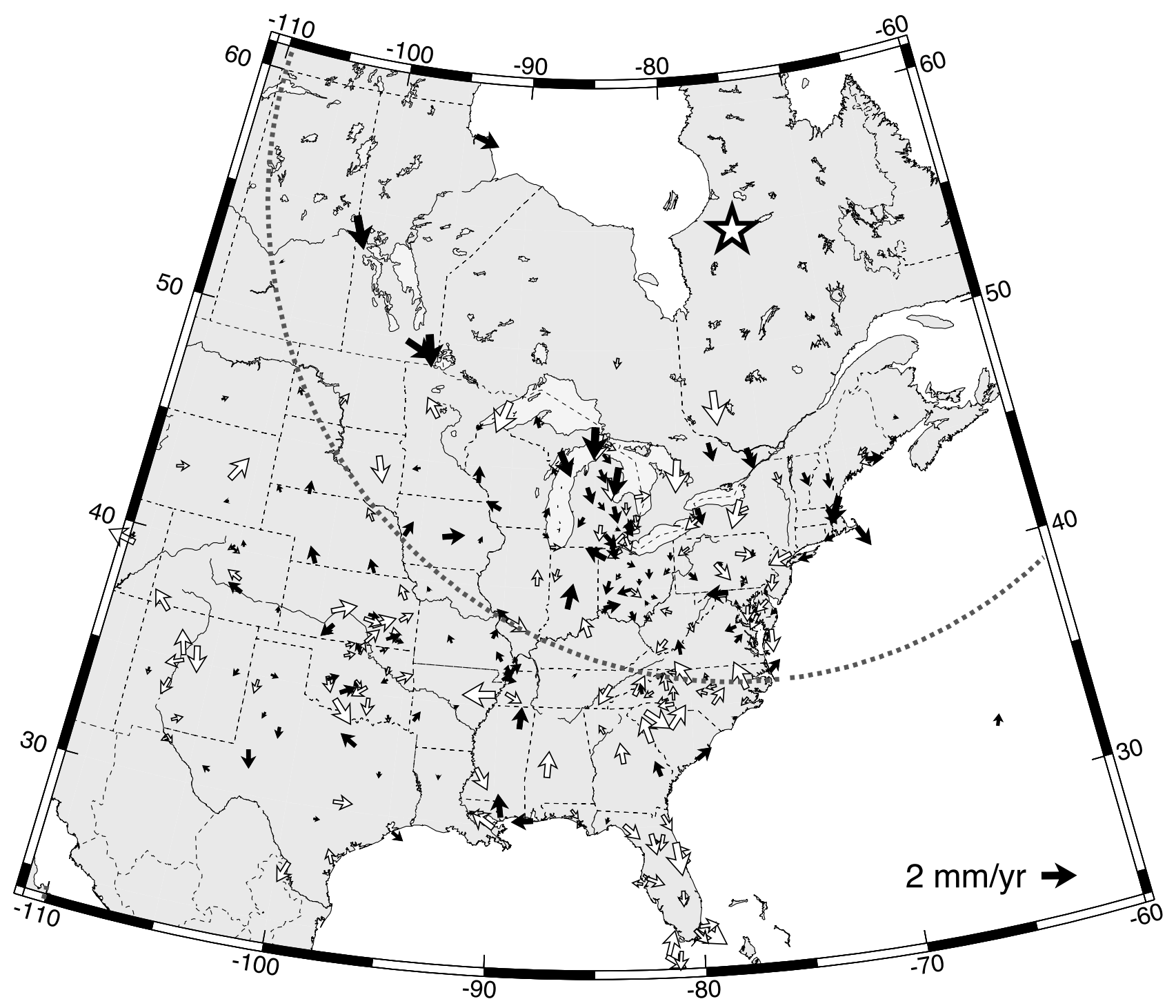

Figure 13. Residual velocities with uncertainty ellipses omitted for a sake of clarity. Best quality sites (random walk noise magnitude $<1 \mathrm{~mm} / \sqrt{\mathrm{yr}}$ or category A monuments) are shown with black arrows, other sites with white arrows. The dashed circle has a radius of $2100 \mathrm{~km}$ and is centered on the GIA uplift (star).

[42] We applied this spatial filtering scheme to the residual velocities described above, using search radii $d_{S}$ ranging from $100 \mathrm{~km}$ to $1000 \mathrm{~km}$. Several interesting patterns emerge from the spatially averaged residual velocity field. Independent of the assumed value for $d_{S}$, the residual velocity field is dominated by the pattern of south to southeastward trending velocities in Canada and the NE United States at rates up to $1.5 \mathrm{~mm} \mathrm{yr}^{-1}$ (Figure 15). This confirms the previously described regional coherence of the south to southeastward residual velocities for sites in the northeastern United States and eastern Canada and constitutes a robust long-wavelength feature of the North American GPS velocity field, limited largely to areas within $2100 \mathrm{~km}$ of the GIA uplift center. This feature is discussed in section 3.5 .

[43] At distances farther than $2100 \mathrm{~km}$ from the GIA uplift center, nearly all of the spatially averaged residual velocities converge to values smaller than $0.5 \mathrm{~mm} \mathrm{yr}^{-1}$ for all averaging radii greater than $300 \mathrm{~km}$ (Figure 15). This indicates an absence of coherent intraplate deformation at long wavelengths and rates exceeding several tenths of a millimeter per year, thereby defining the nominally undeforming plate interior. Features in the velocity field with wavelengths shorter than several hundred $\mathrm{km}$ are severely attenuated by this procedure, thereby necessitating examination of the unfiltered residual velocities for areas such as the New Madrid Seismic Zone, where localized strain may occur (see section 5).

[44] There are three notable exceptions to a random pattern of residual velocities farther than $2100 \mathrm{~km}$ from the GIA uplift center. An east-west belt of north directed residual velocities with magnitudes of $0.2-0.3 \mathrm{~mm} \mathrm{yr}^{-1}$ extends west from Illinois through Iowa, Nebraska, and into Colorado. Similarly slow, but northeast directed residual site motions are observed in Kansas and Oklahoma. Finally, seaward directed residual site motions at rates up to 

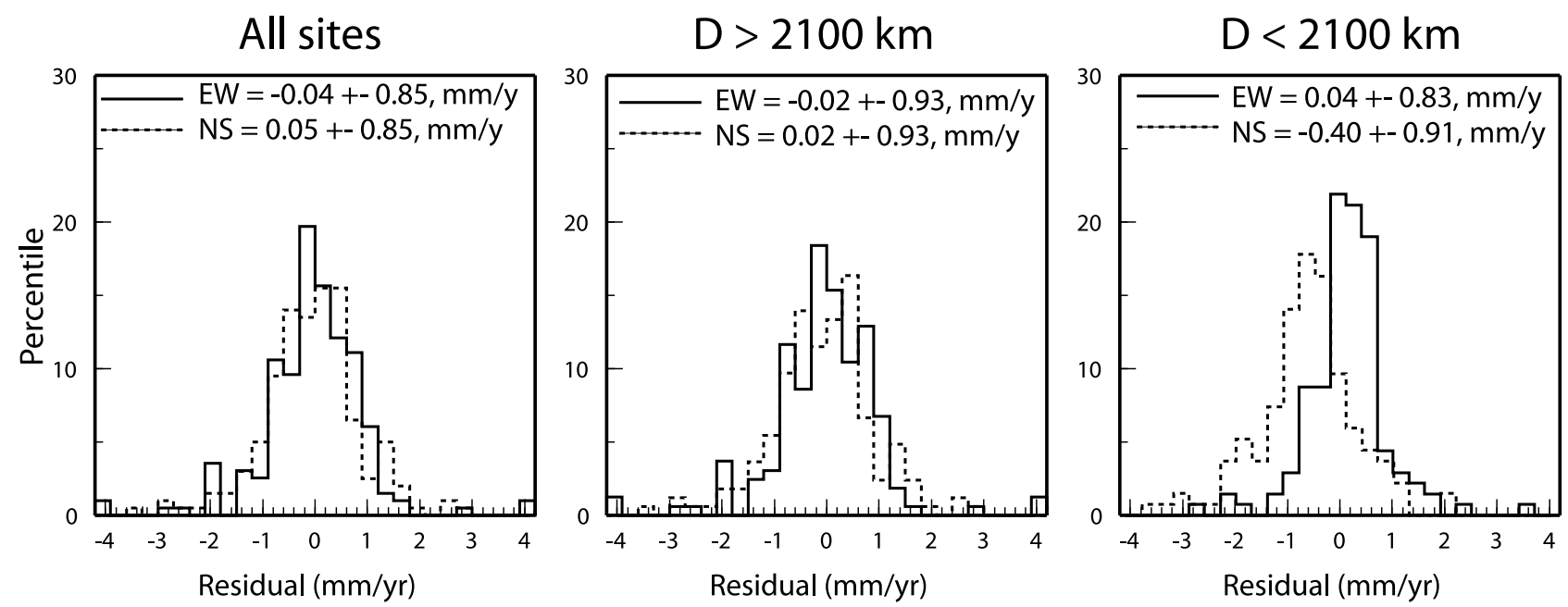

Figure 14. Distribution of residual station velocities (left) for all the sites considered in this study, (middle) for sites located more than $2100 \mathrm{~km}$ away from the assumed GIA center $\left(55^{\circ} \mathrm{N}, 75^{\circ} \mathrm{W}\right)$, and (right) for sites located within $2100 \mathrm{~km}$ from the assumed GIA center.

$0.4 \mathrm{~mm} \mathrm{yr}^{-1}$ are observed in the Gulf Coast states of Florida, Alabama, and Louisiana. These features may result from geophysical processes such as long-wavelength effects of GIA or flexural response to sediment loading in the Gulf, or may be an artefact of systematic correlated errors in the GPS analysis. Given the small magnitude of these residuals, longer time series are necessary to further investigate their origin.

\subsection{Testing Strain Models}

\subsubsection{Bounds on Plate-Wide and Regional Uniform Strain}

[45] If distributed deformation occurs in the plate interior, as appears to be the case (Figure 15), the raw GPS velocity field (in ITRF2000) should be better fit by a model that includes a strain component in addition to a rigid rotation. Below, we test three hypothetical strain fields: (1) uniform strain in the north-south direction, (2) uniform strain in the east-west direction, and (3) uniform radial strain centered on the GIA maximum. We calculate, for each strain field tested, a priori corrections to the raw velocities, then invert the corrected velocities for a best fitting angular velocity. We quantify whether models that include strain and rigid rotation fit the data significantly better than strain free models using an $\mathrm{F}$ test:

$$
F=\frac{\left(\chi_{3 p}^{2}-\chi_{4 p}^{2}\right) /(4-3)}{\chi_{4 p}^{2} /(2 N-4)}
$$

where $N$ is the number of GPS sites used in the estimation, and $\chi_{3 p}^{2}$ and $\chi_{4 p}^{2}$ the $\chi^{2}$ values for the three-parameter and four-parameter models, respectively. The significance level associated with the observed improvement in fit is determined by comparing the observed $\mathrm{F}$ value to that expected for $F(1,2 N-4)$.

[46] Figure 16 and Table 2 summarize the results for the uniform east-west, north-south, and radial strain models tested. For all three models and all velocity subsets we considered, the data are inconsistent with uniform strain (shortening or stretching) at rates that exceed $10^{-9} \mathrm{yr}^{-1}$. Allowing for uniform north-south strain significantly improves the fit to the entire data set and leads to even more significant improvements in fit for the northeastern United States alone, an area than spans the $2100 \mathrm{~km}$ divide discussed above. For all stations in the study area, a model that corrects velocities for $2 \pm 1 \times 10^{-10} \mathrm{yr}^{-1}$ (95\% limit) of north-to-south shortening prior to their inversion for a best fitting angular velocity vector yields the best fit. The velocities from 63 sites in New England are consistent with the existence of north-south and/or radial shortening at strain rates of $8 \pm 2 \times 10^{-10} \mathrm{yr}^{-1}$ (Figure 16). Allowing for strain does not improve the fit, however, when the northern or southern parts of the study area are taken separately. This indicates that the north-to-south shortening that is required by the entire data set is localized along the boundary between the northern and southern domains of the study area, consistent with results reported in sections 3.2 and 3.3. No similar improvement in the fit occurs when east-west strain is assumed to affect the 220 station velocities from the whole study area. The best fit strain rate differs insignificantly from zero and the available velocities impose an upper $95 \%$ limit of $1.5 \times 10^{-10} \mathrm{yr}^{-1}$ on any eastwest stretching and an even more severe upper limit of $\sim 0$ $\times 10^{-10} \mathrm{yr}^{-1}$ of east-west shortening. For the $3100 \mathrm{~km}$ eastto-west width of the study area, these strain rates correspond to maximum integrated velocities of $0.5 \mathrm{~mm} \mathrm{yr}^{-1}$ for stretching and $0 \mathrm{~mm} \mathrm{yr}^{-1}$ for shortening.

[47] The $0.5 \mathrm{~mm} \mathrm{yr}^{-1}$ upper bound on east-west integrated deformation across central North America, corresponding to a maximum strain rate of $1.5 \times 10^{-10} \mathrm{yr}^{-1}$ across the plate interior, is to our knowledge the first estimate that imposes clear upper limits on possible patterns of deformation that might be hiding in the North American plate GPS velocity field. Relative to the $2 \mathrm{~mm} \mathrm{yr}^{-1} 95 \%$ upper bound estimated for the plate interior by previous authors, the bound we estimate for any east-west deformation is a factor of four smaller. The bounds found here for intraplate strain are consistent with values derived from historical seismicity in the eastern United States $\left(10^{-12}\right.$ to $10^{-10} \mathrm{yr}^{-1}$ [Anderson, 


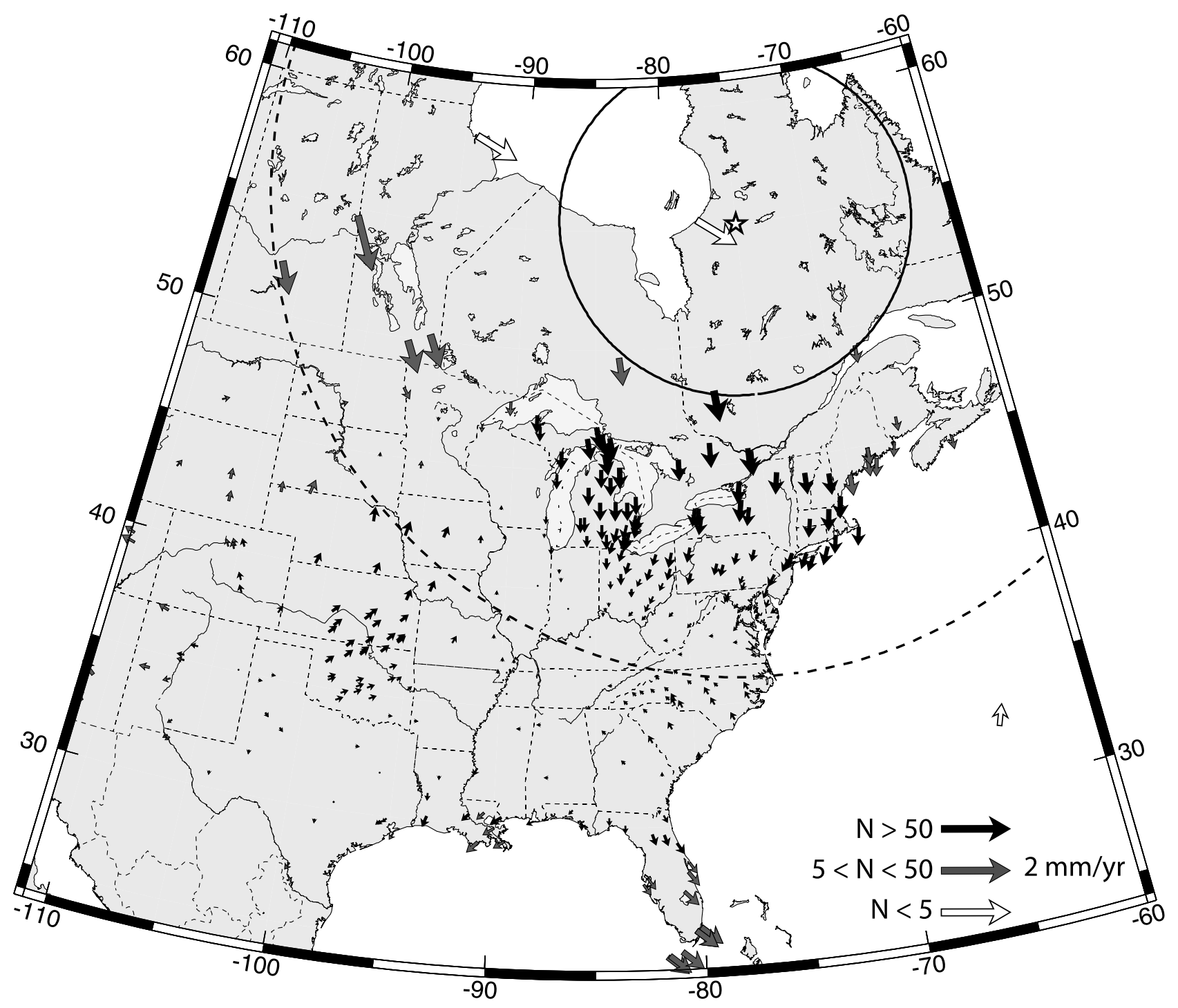

Figure 15. Spatially averaged residual velocities calculated using a nearest neighbor scheme with a search radius of $800 \mathrm{~km}$. The dashed circle has a radius of $2100 \mathrm{~km}$ and is centered on the GIA uplift (star). A solid circle with a $800 \mathrm{~km}$ radius is shown to illustrate the search radius dimension. Arrow shading represents the number $(\mathrm{N})$ of residual velocities that are averaged to calculate each residual velocity.

1986]) and eastern Canada $\left(10^{-13}\right.$ to $10^{-10} \mathrm{yr}^{-1}$ [Mazzotti and Adams, 2005]).

\subsubsection{Bounds on Strain From GIA}

[48] Given that the strongest plate-wide deformation signal is likely to result from GIA, we also tested a radial strain model that simulates GIA deformation as the sum of two Gaussian functions. Horizontal velocities are modeled as

$$
V_{r h}=A_{e}\left(e^{-\left(\left(r-R_{e}\right) / W_{e}\right)^{2}}-e^{-\left((r+R e) / W_{e}\right)^{2}}\right)+A_{c} e^{-\left(\left(r-R_{c}\right) / W_{c}\right)^{2}}
$$

where $r$ is the radial distance to the GIA center, $A_{e}$ is the magnitude of the maximum positive velocity in the uplift area, $R_{e}$ its distance with respect to the GIA center, $W_{e}$ the characteristic decay distance in the uplift area, $A_{c}$ the magnitude of the maximum negative velocity in the forebulge, $R_{c}$ its distance with respect to the GIA center, and $W_{c}$ the characteristic decay distance in the forebulge. Similarly, vertical velocities are modeled as

$$
V_{u p}=A_{u} e^{-\left(r / W_{u}\right)^{2}}+A_{s} e^{-\left(\left(r-R_{s}\right) / W_{s}\right)^{2}}
$$

where $A_{u}$ is the maximum uplift rate, $R_{s}$ the distance from that maximum to the GIA center, $W_{u}$ the characteristic decay distance in the uplift area, $A_{s}$ the maximum subsidence rate, and $W_{s}$ the characteristic decay distance in the forebulge. This simple geometrical model is obviously not meant to reproduce the physical processes at work, but to test whether the data are consistent with a GIA-like pattern using only 5 (vertical) and 6 (horizontal) parameters, in addition to the 3 rigid rotation parameters. In the search of the best fit parameters, we keep the location of the GIA 

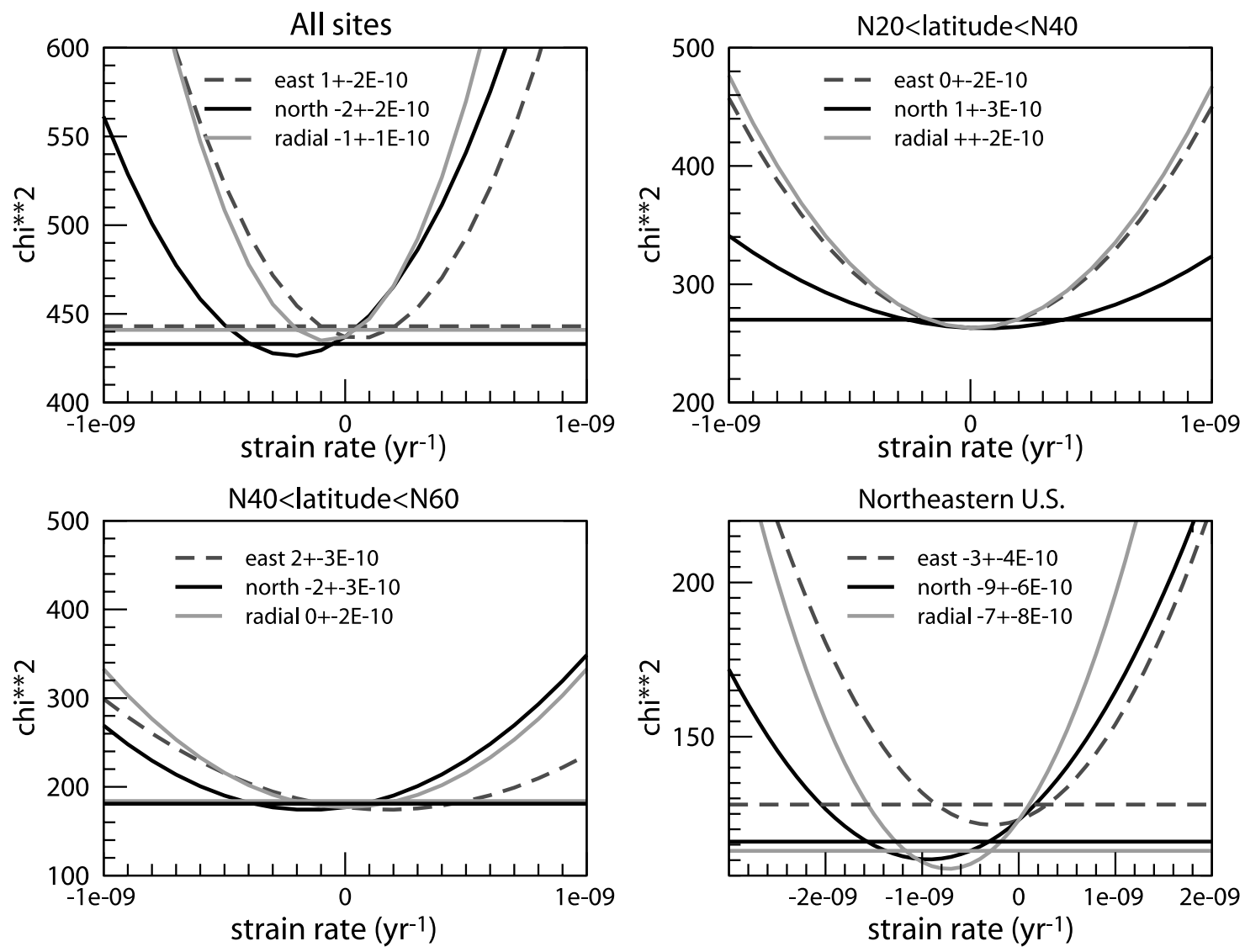

Figure 16. The $\chi^{2}$ as a function of strain rate for a series of models that include rigid rotation and strain (explanations in the text). The horizontal lines show the 95\% confidence level for each model tested. Positive strain rates indicate extension; negative strain rates indicate compression. (bottom right) The northeastern United States comprising sites from $35^{\circ} \mathrm{N}-43^{\circ} \mathrm{N}$ and $85^{\circ} \mathrm{W}-75^{\circ} \mathrm{W}$.

center fixed to $\mathrm{W} 75^{\circ} / \mathrm{N} 55^{\circ}$. The best fit model parameters are listed in Table 3. We find that this simple model fits the velocity field best among all the strain rate fields tested. An $F$ test shows that the $\chi^{2}$ decrease with the additional free parameters is significant at more than the $99 \%$ confidence level. Figure 17 (bottom) shows the best fit model for horizontal velocities as a function of distance to the GIA center. The negative slope at radial distances of 1000 $2200 \mathrm{~km}$ corresponds to radial shortening at a rate of about $10^{-9} \mathrm{yr}^{-1}$, consistent with the radial shortening model shown in Figure 16 for the northeastern United States.
[49] The choice of a single GIA center for the above analysis is clearly a simplification, as recent Laurentide ice models show a deglaciation pattern with independent ice centers west of Hudson Bay in addition to the one used here, located in northern Québec [e.g., Peltier, 2004]. These multiple ice centers lead to a more complex deformation pattern than a simple radial field, which may actually explain some of the nonradial residuals found at sites in central Canada and north central United States (Figures 13 and 15). However, the lack of data in central Canada and north central United States in the present study precludes a

Table 2. Statistical Tests for Significance of Best Intraplate Strain Models ${ }^{\mathrm{a}}$

\begin{tabular}{lcccc}
\hline & & \multicolumn{2}{c}{ Velocity Subset } \\
\cline { 2 - 5 } \multicolumn{1}{c}{ Strain Model } & All Sites & $<40^{\circ} \mathrm{N}$ & $>40^{\circ} \mathrm{N}$ & NE United States \\
\hline Number of sites & 220 & 133 & 90 & 63 \\
Uniform east-west strain, \% & 65 & 100 & 10 & 22 \\
Uniform north-south strain, \% & 0.1 & 68 & 10 & 0.03 \\
Uniform strain centered on GIA maximum, \% & 16 & 100 & 100 & 0.004 \\
\hline
\end{tabular}

${ }^{a}$ Numbers express the probability that the GPS station velocities from the stated geographic areas are consistent with zero strain rate within their uncertainties. Probability is determined using an $\mathrm{F}$ ratio test that compares the least squares misfits to the station velocities for zero strain rate (e.g., no deformation of the plate interior) to the strain rate that allows for the best least squares fit to the velocities for an assumed strain model. Probabilities take on values from 0 to $100 \%$, with smaller values corresponding to increasingly low probabilities that the data are consistent with a rigid plate interior. 
Table 3. Best Fit Parameters of the Gaussian Curve Fit Model to the GPS Velocities

\begin{tabular}{ccccc}
\hline & \multicolumn{2}{c}{ Horizontal } & & \multicolumn{2}{c}{ Vertical } \\
\cline { 5 - 5 } Parameter & Value & & Parameter & Value \\
\hline$A_{e}$ & $0.80 \mathrm{~mm} / \mathrm{yr}$ & & $A_{u}$ & $13.25 \mathrm{~mm} / \mathrm{yr}$ \\
$R_{e}$ & $900 \mathrm{~km}$ & & & \\
$W_{e}$ & $500 \mathrm{~km}$ & & $W_{u}$ & $900 \mathrm{~km}$ \\
$A_{c}$ & $-0.25 \mathrm{~mm} / \mathrm{yr}$ & & $A_{s}$ & $-1.45 \mathrm{~mm} / \mathrm{yr}$ \\
$R_{c}$ & $2300 \mathrm{~km}$ & & $R_{s}$ & $2100 \mathrm{~km}$ \\
$W_{c}$ & $1100 \mathrm{~km}$ & $W_{s}$ & $1100 \mathrm{~km}$ \\
\hline
\end{tabular}

robust analysis of GIA effects east of about $90^{\circ} \mathrm{W}$ and the use of more complex models.

\subsubsection{Bounds on Regional Strain Rates}

[50] Finally, we estimate strain rates in the North American plate interior using a robust approach fully described by England and Molnar [1997]. We divide the GPS network into triangular regions, assume that strain within each triangle is uniform (i.e., site velocities within each triangle vary linearly with latitude and longitude), and invert all residual velocities within each triangle to estimate best fit velocities and their formal errors at the triangle vertices. Velocities at the triangle vertices are then used to determine the best strain rate tensor for each triangle. This method fully exploits the kinematic information from all GPS sites within the triangle and moreover allows the user to select locations of the triangle vertices based on the density and locations of GPS sites with respect to the strain anomalies being investigated. Readers are referred to England and Molnar [1997] for a full description of the method.

[51] We applied the above procedure to the observed residual velocities (Figure 18) using triangles selected to detect any strain across the GIA bulge in southern Canada and the northern United States. Residual velocities that are interpolated to the triangle vertices located south of $40^{\circ} \mathrm{N}$ are zero within errors, whereas residual velocities at locations farther north are larger and point south to southeast. These agree with the spatial filtering results discussed above. The principal strains show a band of approximately north-south shortening at a rate on the order of $10^{-9} \mathrm{yr}^{-1}$ in the northeastern United States and just south and west of the Great Lakes, consistent with the previously described shortening that occurs across the periphery of the currently uplifting area (Figure 19). A similar feature has recently been detected in Europe around the Fennoscandian postglacial uplift [Nocquet et al., 2005], with similar shortening rates.

[52] These higher strain rates in the northeastern United States and southern Québec (compared to the plate-wide estimate reported above) are geographically consistent with the area of higher historical seismic moment release reported by Mazzotti and Adams [2005] in southeastern Canada. The NNW-SSE to NW-SE compression directions found here in the two triangles encompassing the St. Lawrence seismic zone are consistent with compressional earthquake focal mechanisms and their N-S to NW-SE P axis [Bent et al., 2003]. In addition, we find strain rates in these triangles that are consistent with the lower end of the
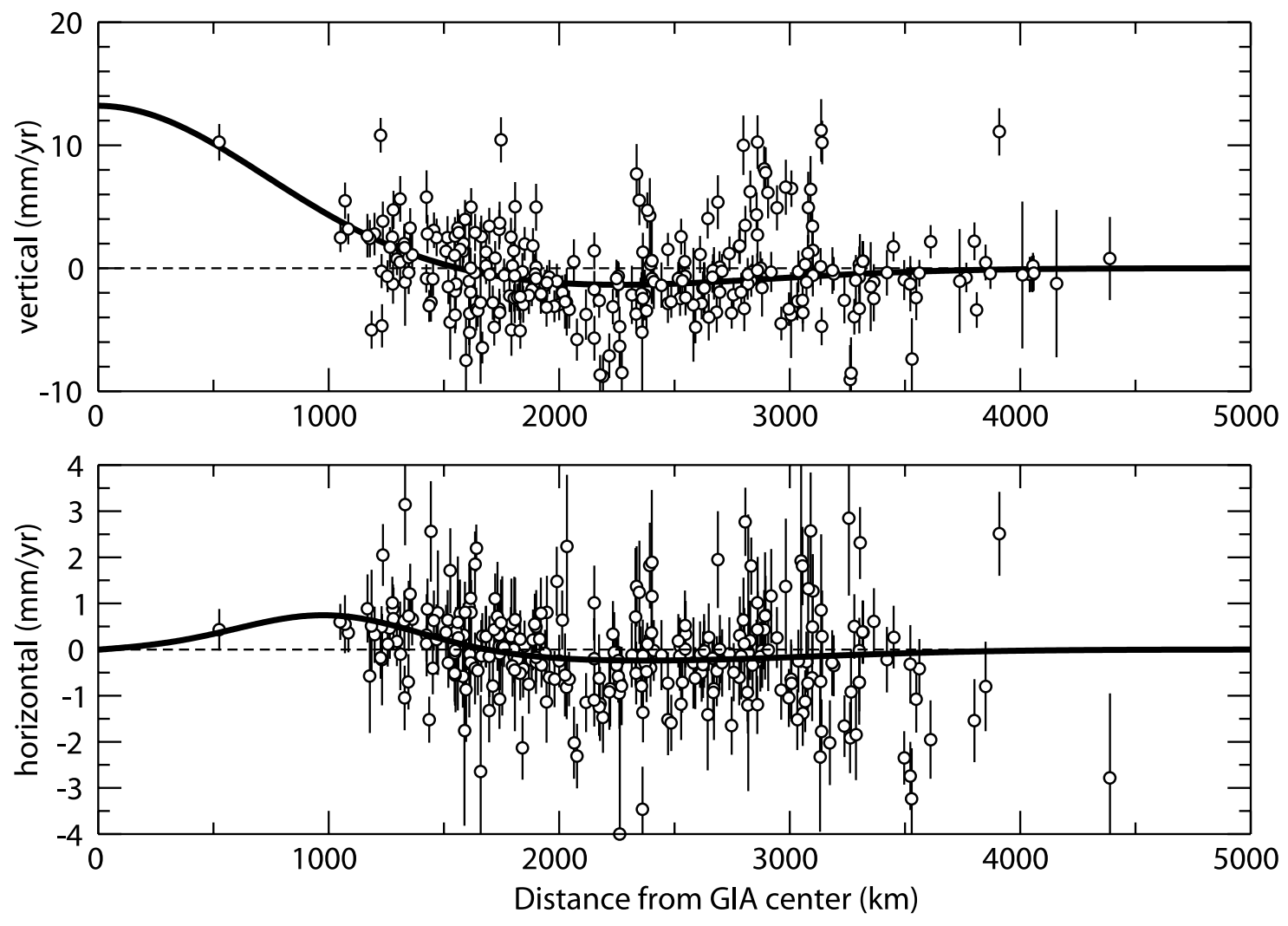

Figure 17. Profiles of (top) vertical site rates and (bottom) residual horizontal velocities as a function of distance to the assumed GIA center $\left(55^{\circ} \mathrm{N}, 75^{\circ} \mathrm{W}\right)$. Black lines are exponential fits to the data. 


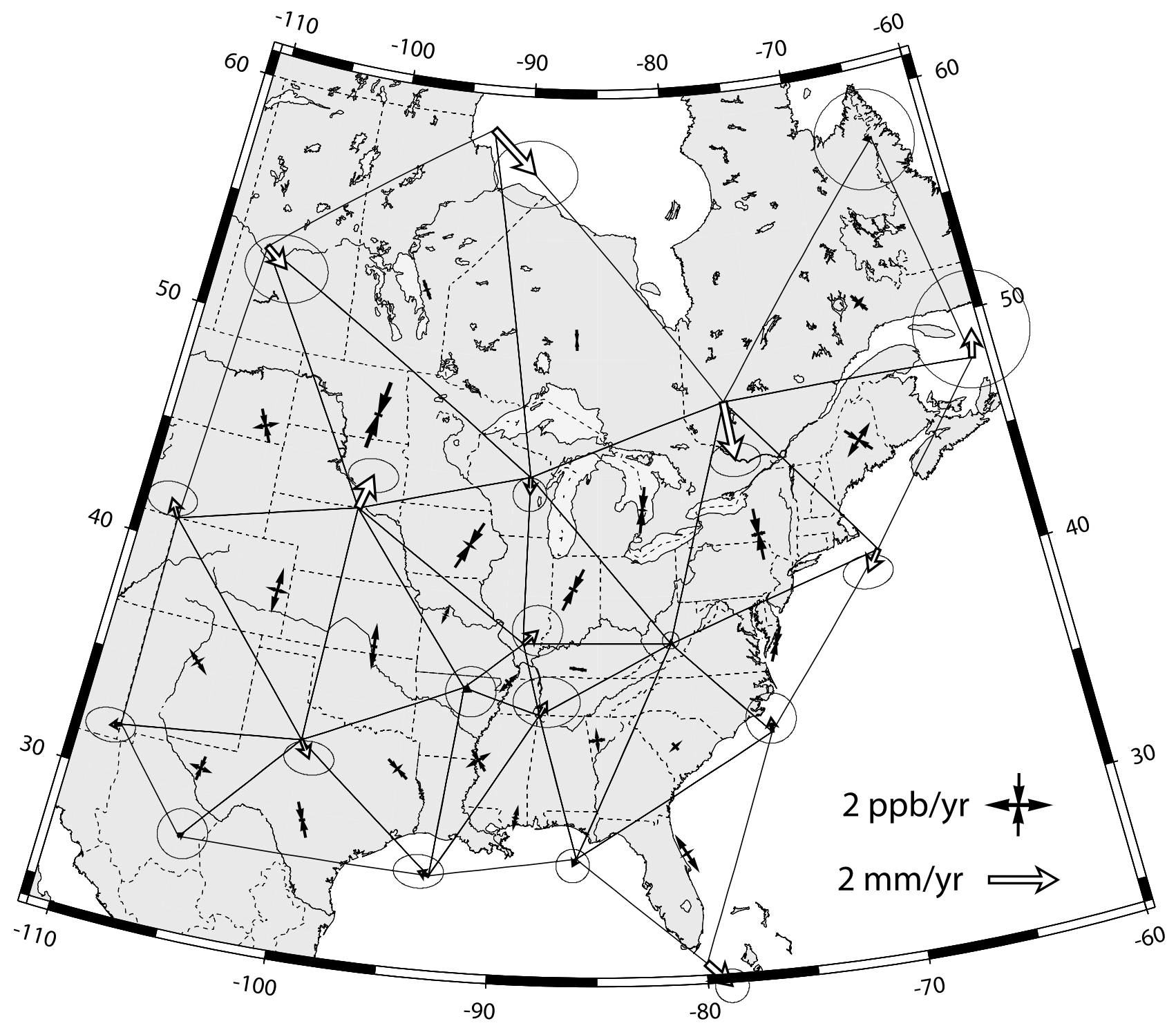

Figure 18. Residual velocity field interpolated to triangle vertices and corresponding principal strains.

$1-4 \times 10^{-9} \mathrm{yr}^{-1}$ rates reported by Mazzotti et al. [2005] in the St. Lawrence region on the basis of denser GPS campaign measurements. Differences between the two approaches could result from biases in campaign measurements or from the lack of resolution imposed by the sparse spatial coverage of continuous GPS stations in Canada. Although earthquake catalogs in North America are limited to $\sim 500$ years and may not be representative of longer time spans, these comparisons provide an external test for the geodetic results presented here. Also, if the intraplate strain detected here is primarily caused by GIA, as we suspect [see also Mazzotti et al., 2005], the general agreement between geodetic and seismic strain suggests that GIA contributes to intraplate seismicity, at least in southeastern Canada and northeastern United States [Stein et al., 1979, 1989; Hasegawa and Basham, 1989; Wu and Johnston, 2000].

\subsection{Vertical Motions}

[53] Figures 17 and 19 show that vertical motions are consistent with a GIA pattern. We find up to $10 \mathrm{~mm} \mathrm{yr}^{-1}$ of uplift just east of Hudson Bay, consistent with the location of the GIA center proposed by Blewitt et al. (unpublished report, 2005). The maximum uplift rate is however poorly resolved because of the lack of sites near the GIA center. Vertical velocities decay outward to values of zero (the hinge line) at distances of $\sim 1500 \mathrm{~km}$ from the GIA center. Subsidence in the forebulge reaches a maximum of $1.4 \pm$ $0.7 \mathrm{~mm} \mathrm{yr}^{-1}$ at a distance of $2100 \mathrm{~km}$ from the GIA center, consistent with the horizontal velocity profile shown in Figure 17, in which the transition from areas experiencing significant shortening to areas of insignificant strain also occurs at distances of $\sim 2000 \mathrm{~km}$ from the center of GIA uplift. That the best fitting horizontal and vertical models (Figure 17) agree well with each other strongly suggests the horizontal residual site velocities are influenced by GIA and that the vertical velocities are not significantly biased.

\section{The New Madrid Seismic Zone}

\subsection{GPS Results}

[54] Although our residual velocity field for the central and eastern United States shows no obvious pattern of 


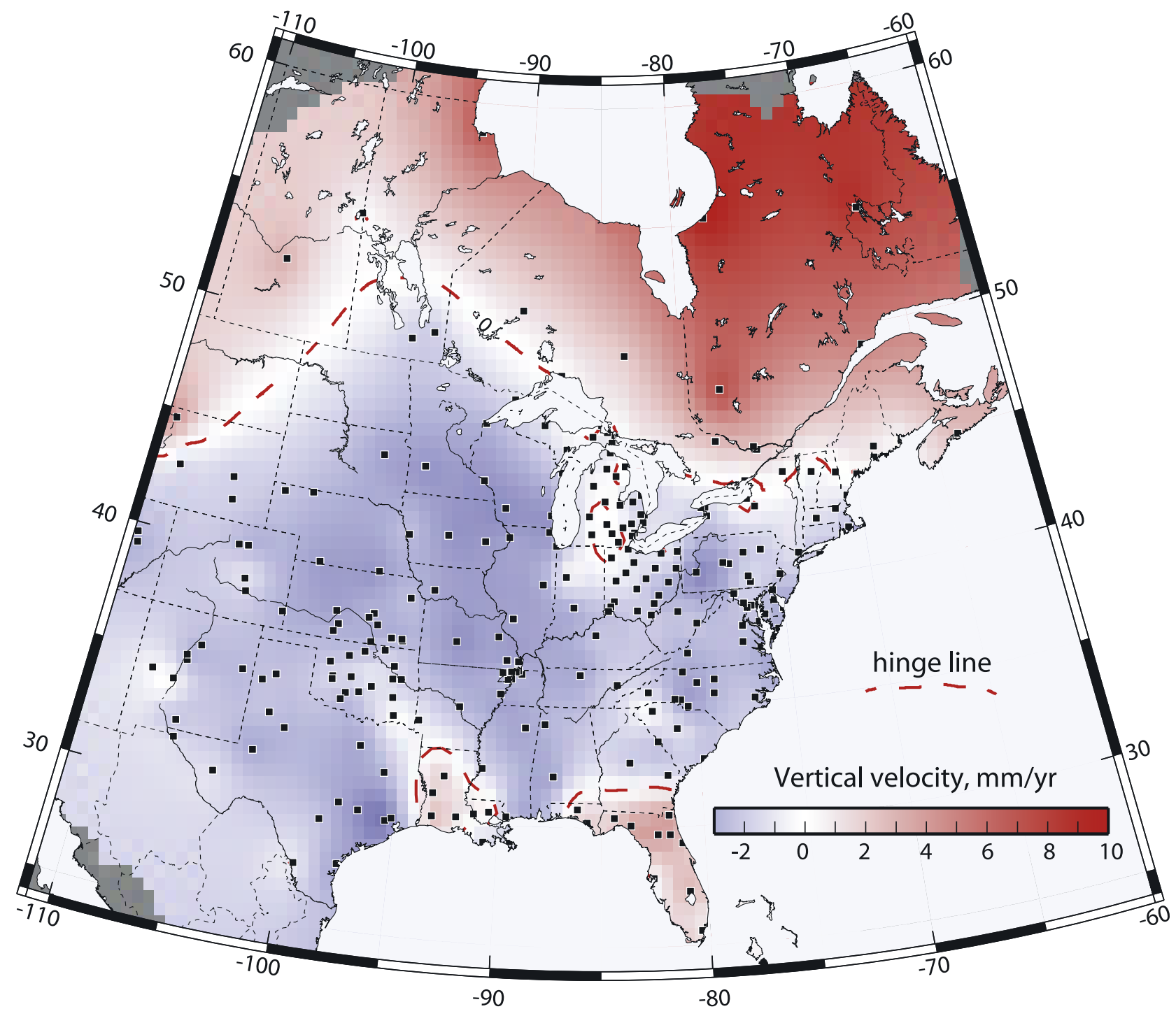

Figure 19. Interpolated vertical velocities. Only sites with random walk noise magnitude $<1 \mathrm{~mm} / \sqrt{\mathrm{yr}}$, category A sites, and sites with vertical velocity standard deviation less than $1.5 \mathrm{~mm} / \mathrm{yr}$ are used. Black squares show the site locations. The red dashed line corresponds to zero velocity (hinge line). The interpolation scheme uses an adjustable tension continuous curvature surface gridding algorithm with a tension factor of 0.9 .

regional-scale strain, the existence of regions of significant localized strain in the central and eastern United States has been suggested by several authors. For instance, using a GPS triangulation comparison, Liu et al. [1992] found a shear strain rate of $0.108 \pm 0.045 \mu \mathrm{rad}^{-1} \mathrm{r}^{-1}$ in the southern part of the New Madrid Seismic Zone (NMSZ), corresponding to a slip rate of 5 to $7 \mathrm{~mm} \mathrm{yr}^{-1}$. However, using similar data in the northern part of the NMSZ, Snay et al. [1994] found strain rates of $0.030 \pm 0.019 \mu \mathrm{rad} \mathrm{yr}^{-1}$, indistinguishable from zero. Similarly, Weber et al. [1998] and Newman et al. [1999], using GPS data from campaigns performed between 1991 and 1997, found a slip rate of 0.2 $\pm 2.4 \mathrm{~mm} \mathrm{yr}^{-1}$ in the NMSZ. Gan and Prescott [2001] analyzed GPS data from continuous GPS stations in the central and eastern United States and argue for significant deviations from rigid plate behavior in the Mississippi embayment, which they interpret as evidence for elevated strain rates. More recently, Smalley et al. [2005] propose that relative motions between CGPS sites in the NMSZ are significant and comparable to deformation rates along active plate boundaries.

[55] Our results show no detectable residual motion in the NMSZ at the 95\% confidence level (Figure 20). The average weighted-residual for sites in the region with respect to the predictions of our best fitting North American plate angular velocity vector is $0.7 \mathrm{~mm} \mathrm{yr}^{-1}$, comparable to that for sites outside the region. None of the individual site velocities are significant at the $95 \%$ confidence level.

[56] A key question is whether the apparent shortening of $1.6 \pm 1.2 \mathrm{~mm} \mathrm{yr}^{-1}$ (68\% confidence) between sites RLAP and NWCC across the Reelfoot fault is significant, as recently proposed by Smalley et al. [2005]. An examination 


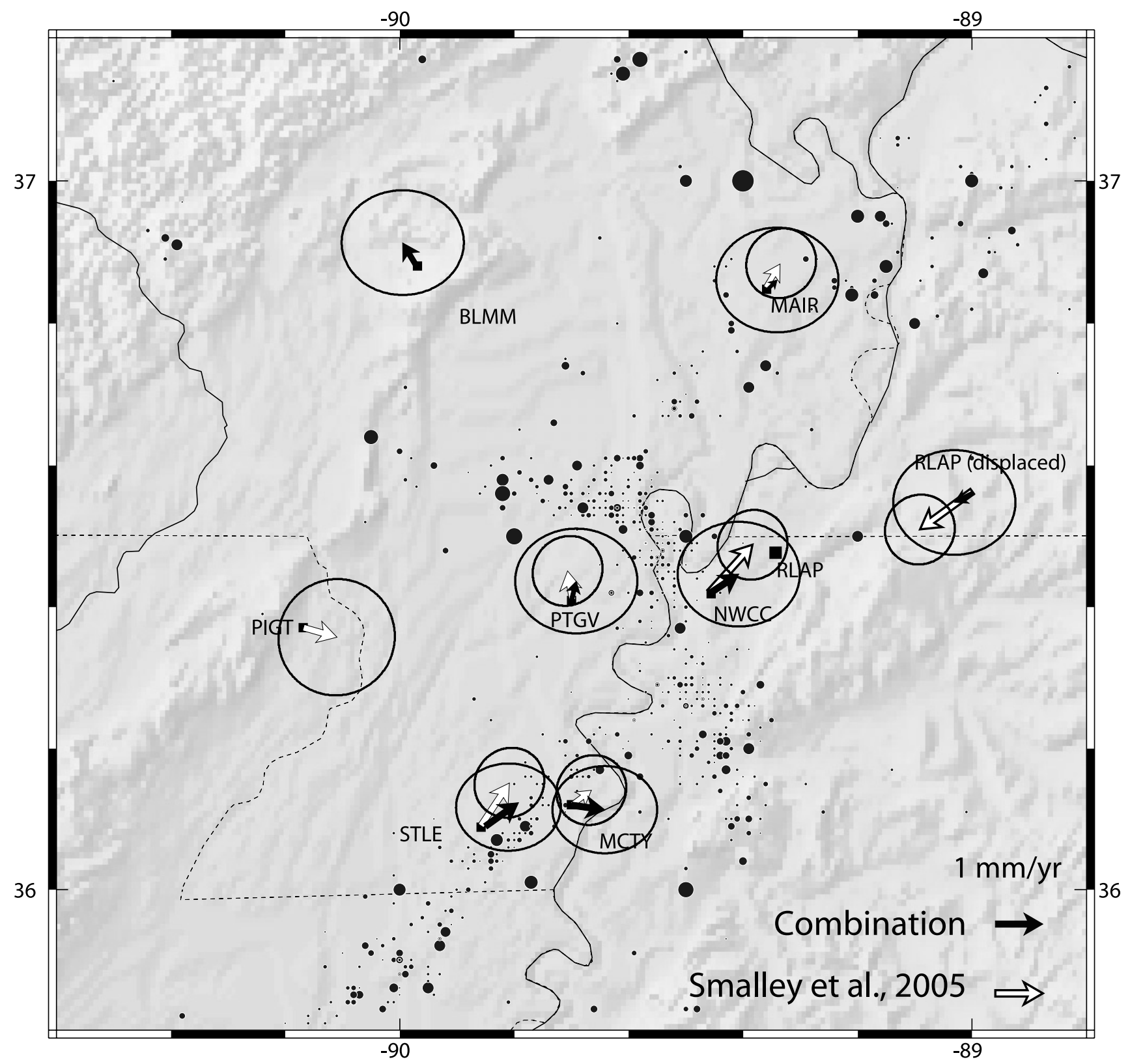

Figure 20. Residual velocities in the NMSZ. The individual GAMIT and GIPSY solutions are shown together with the combined solution and the velocities published by Smalley et al. [2005]. Seismicity is from the CERI catalog.

of the baseline time series between these two sites (Figure 21) suggests that the apparent shortening is not caused by a linear decrease in the interstation distance, as might be expected if the cause of the shortening was tectonic, but is instead a result of an $8 \mathrm{~mm}$ offset between 2001 and 2002 that separates two periods of no discernible change in the baseline length. The offset, which originated at site NWCC, does not correspond to any equipment changes, significant earthquakes, or known creep events at or near site NWCC and is thus difficult to explain. Whatever the explanation, the apparent shortening between RLAP and NWCC reported here as well as by Smalley et al. [2005] results from this unexplained offset and is unlikely to represent steady, long-term strain accumulation on the intervening Reelfoot fault.

\subsection{Implications for Earthquake Recurrence}

[57] On the basis of our $0.7 \mathrm{~mm} \mathrm{yr}^{-1}$ weighted RMS value for the residual velocities of the NMSZ sites, random deviations from a rigid plate model in the NMSZ region do not exceed $1.4 \mathrm{~mm} \mathrm{yr}^{-1}$ at the $95 \%$ confidence level. We assume that this represents a conservative upper bound on the magnitude of any long-term slip in the study area. Assuming a simple model where characteristic earthquakes repeat regularly on a given active fault, as is implicit in the United States earthquake hazard maps, for instance, our 


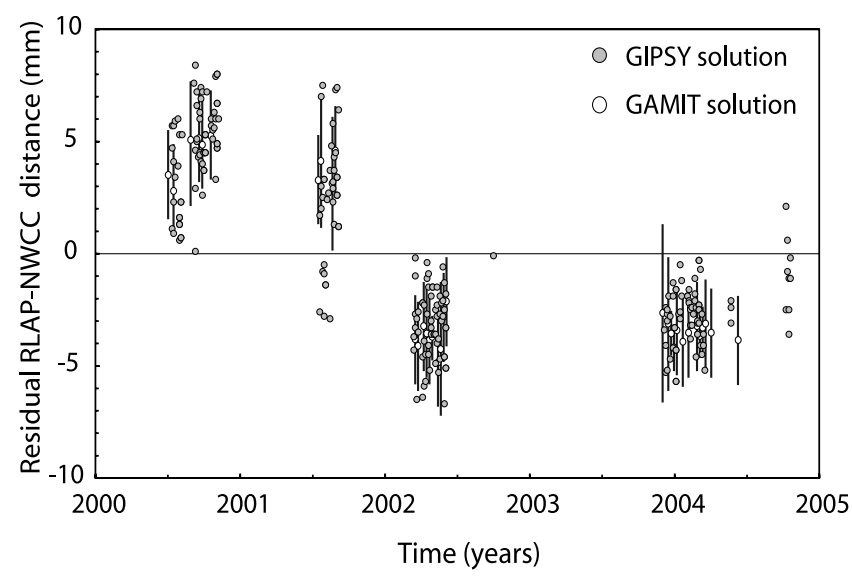

Figure 21. NWCC-RLAP baseline length time series (weekly solutions).

results imply a minimum repeat time of about 3,000 to 8,000 years for future magnitude 8 earthquakes with $5-10$ $\mathrm{m}$ of coseismic slip (Figure 22). For comparison, National Seismic Hazard maps [Frankel et al., 1996] assume a 1000 year recurrence time for M8 events with $5 \mathrm{~m}$ of coseismic slip. The implied $\sim 5 \mathrm{~mm} \mathrm{yr}^{-1}$ of long-term slip rate on the New Madrid faults is a factor of four faster than the upper bound suggested by our analysis.

[58] Similarly, our $1.4 \mathrm{~mm} \mathrm{yr}^{-1}$ upper bound implies a minimum repeat time of $600-1500$ years for future magnitude 7 earthquakes with 1-2 $\mathrm{m}$ of coseismic slip (Figure 22). This is consistent with recent and historic earthquake catalogs, which predict a recurrence interval that exceeds 1000 years for magnitude 7 earthquakes, and 10,000 years for magnitude 8 earthquakes [Newman et al., 1999]. It is also consistent with paleoseismic data [Kelson et al., 1994; Tuttle and Schweig, 1995; Tuttle et al., 1999], which imply recurrence intervals of 400 to 1000 years.

\section{Conclusions}

[59] Our analysis of data from more than 300 continuous GPS sites in the North American plate interior indicates that the velocity field is described within uncertainties by a simple rigid plate rotation that is modified in some areas by a deformation pattern consistent with glacial isostatic rebound. After correcting the individual GPS station velocities for the predicted motion of the North American plate, residual horizontal velocities reach $\sim 0.8 \mathrm{~mm} \mathrm{yr}^{-1}$ close to the GIA center and decrease outward in a quasiradial pattern. Analysis of the residual velocity field reveals a significant, north-to-south deformation gradient of $\sim 1 \mathrm{~mm} \mathrm{yr}^{-1}$, primarily localized between 1000 and $2200 \mathrm{~km}$ from the GIA center and corresponding to strain rates of about $10^{-9} \mathrm{yr}^{-1}$. At distances farther than $2100 \mathrm{~km}$ from the GIA center, horizontal residual velocities are random and exhibit no evidence for regions of elevated strain rates. In particular, we find no detectable residual motion at the $95 \%$ confidence level in the New Madrid Seismic Zone, where the average weighted misfit of $0.7 \mathrm{~mm} \mathrm{yr}^{-1}$ is the same as the weighted misfit of our rigid plate model. The numerous velocities impose severe upper (95\%) bounds of $1.5 \times 10^{-10} \mathrm{yr}^{-1}$ on east-west uniform strain rates in eastern and central North America. The implied, integrated deformation rate across the plate interior is less than $0.5 \mathrm{~mm} \mathrm{yr}^{-1}$, a factor of four smaller than upper bounds estimated by previous authors.

[60] Our results compare well with those reported for other plate interiors. In Western Europe, magnitude 7 paleoearthquakes are inferred in the Rhine graben, but no surface deformation has yet been resolved with GPS at the $0.8 \mathrm{~mm} \mathrm{yr}^{-1}$ level [Nocquet et al., 2005]. GPS measurements in Australia also show no deformation within their $0.8 \mathrm{~mm} \mathrm{yr}^{-1}$ resolution [Beavan et al., 2002], despite several significant earthquakes in the past two decades. Although the instrumental and paleoseismological record of intraplate earthquakes indicates that tectonic stresses within plate interiors accumulate on faults and are released during large infrequent events, geodetic observations on several major plates have not yet been able to resolve the associated surface deformation. Interseismic strain loading of faults in plate interiors may thus be smaller than the present GPS detection threshold, or strain accumulation may occur mostly at depth through transient processes that may have little to no surface signature, as proposed by Kenner and Segall [2000] for the New Madrid area.

[61] Our results reveal the existence of significant horizontal and vertical deformation associated with glacial isostatic adjustment, extending as far as $2100 \mathrm{~km}$ from the assumed center of GIA uplift just east of Hudson Bay. Although a rigorous comparison of the 3-D deformation constraints that our residual velocities impose on GIA deformation is beyond the scope of this paper, a first-order comparison with the predictions of the VM1 and VM2 endmember models described by Peltier [1998] suggests that model VM1 is more consistent with the observed absence of any GIA effects south of $40^{\circ} \mathrm{N}$ (Figure 15) than is model VM2. In this regard, our results agree with conclusions reached by Argus et al. [1999] regarding the superior compatibility of the predictions of model VM1 with the

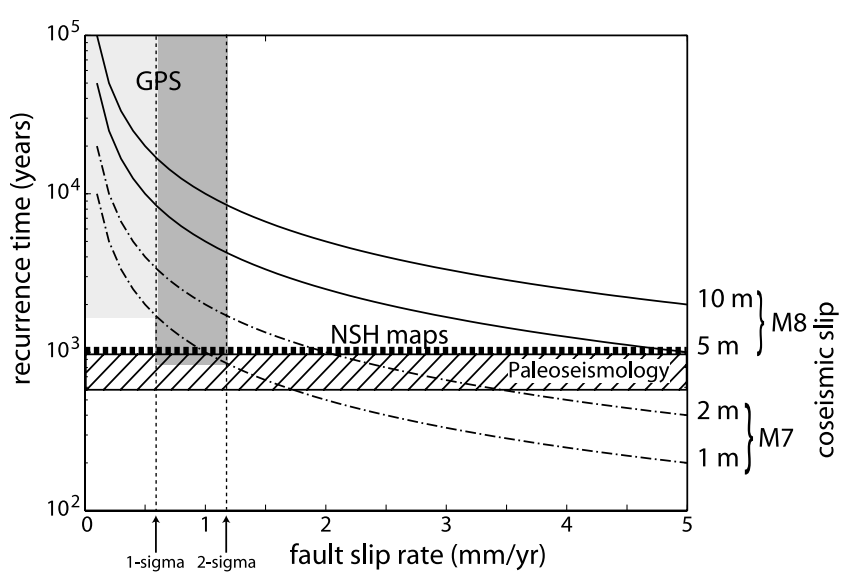

Figure 22. Recurrence time for M7 and M8 earthquakes, with two end-member values of coseismic slip for each magnitude [from Newman et al., 1999]. NSH, National Seismic Hazard maps. Paleoseismology is from Tuttle and Schweig [1995]. 
very long baseline interferometry and satellite laser ranging geodetic constraints they present.

[62] Acknowledgments. This work was supported by the U.S. Geological Survey (USGS), Department of the Interior, under USGS award 03HQGR0001. We thank the NGS for making the CORS data publicly available, CERI for making the GAMA data publicly available, and all agencies participating in the IGS, ranging from data collection to the realization of combined solutions. We also thank the IERS for maintaining a high-accuracy reference frame critical for geophysical applications. Seth Stein, Stéphane Mazzotti, and Associate Editor Steve Cohen are thanked for their insightful reviews.

\section{References}

Altamimi, Z., P. Sillard, and C. Boucher (2002), ITRF2000: A new release of the International Terrestrial Reference Frame for earth science applications, J. Geophys. Res., 107(B10), 2214, doi:10.1029/ 2001JB000561.

Anderson, J. G. (1986), Seismic strain in the central and eastern United States, Bull. Seismol. Soc. Am., 69, 135-158.

Argus, D. F., and R. G. Gordon (1996), Tests of the rigid-plate hypothesis and bounds on intraplate deformation using geodetic data from very long baseline interferometry, J. Geophys. Res., 101, 13,555-13,572.

Argus, D. F., W. R. Peltier, and M. W. Watkins (1999), Glacial isostatic adjustment observed using very long baseline interferometry and satellite laser ranging geodesy, J. Geophys. Res., 104, 29,077-29,093.

Baljinnyam, I., et al. (1993), Ruptures of major earthquakes and active deformation in Mongolia and its surroundings, Geol. Soc. Am., Mem., $181,62 \mathrm{pp}$.

Balz, G., and M. D. Zoback (2001), Did deglaciation trigger intraplate seismicity in the New Madrid Seismic Zone?, Geology, 29, 175-178.

Beavan, J. (2005), Noise properties of continuous GPS data from concrete pillar geodetic monuments in New Zealand and comparison with data from U.S. deep drilled braced monuments, J. Geophys. Res., 110 B08410, doi:10.1029/2005JB003642.

Beavan, J., P. Tregoning, M. Bevis, T. Kato, and C. Meertens (2002), Motion and rigidity of the Pacific Plate and implications for plate boundary deformation, J. Geophys. Res., 107(B10), 2261, doi:10.1029/ 2001JB000282.

Bent, A. L., J. Drysdale, and H. K. C. Perry (2003), Focal mechanisms for eastern Canadian earthquakes: 1994-2000, Seismol. Res. Lett., 74, $449-$ 465 .

Blewitt, G., and D. Lavallée (2002), Effect of annual signals on geodetic velocity, J. Geophys. Res., 107(B7), 2145, doi:10.1029/2001JB000570.

Davis, J. L., and J. X. Mitrovica (1996), Glacial isostatic adjustment and the anomalous tide gauge record of eastern North America, Nature, 379, $331-333$

DeMets, C., R. G. Gordon, D. F. Argus, and S. Stein (1994), Effect of recent revisions to the geomagnetic reversal time scale on estimates of current plate motions, Geophys. Res. Lett., 21, 2191-2194.

Dixon, T. H., A. Mao, and S. Stein (1996), How rigid is the stable interior of the North American plate?, Geophys. Res. Lett., 23, 3035-3038.

Eanes, R. J., and A. Schuler (1999), An improved global ocean tide model from TOPEX/Poseidon altimetry: CSR4.O, paper presented at EGS 24th General Assembly, The Hague, Netherlands.

England, P., and P. Molnar (1997), The field of crustal velocity in Asia calculated from Quaternary rates of slip on faults, Geophys. J. Int., 130, $551-582$

Frankel, A., et al. (1996), National seismic hazard maps documentation, U.S. Geol. Surv. Open File, 96-532.

Fernandes, R. M. S., B. A. C. Ambrosius, R. Noomen, L. Bastos, L. Combrinck, J. M. Miranda, and W. Spakman (2004), Angular velocities of Nubia and Somalia from continuous GPS data: Implications on present-day relative kinematics, Earth Planet. Sci. Lett., 222, 197-208.

Gan, W., and W. H. Prescott (2001), Crustal deformation rates in central and eastern U.S. inferred from GPS, Geophys. Res. Lett., 28, 3733 3736 .

Hasegawa, H. S., and P. Basham (1989), Spatial correlation between seismicity and postglacial rebound in eastern Canada, in Earthquakes at North-Atlantic Passive Margins: Neotectonics and Postglacial Rebound, edited by S. Gregerson and P. Basham, pp. 483-500, Springer, New York.

Hough, S. E., J. G. Armbuster, L. Seeber, and J. F. Hough (2000), On the modified Mercalli intensities and magnitudes of the 1811-1812 New Madrid earthquakes, J. Geophys. Res., 105, 23,839-23,864.

Johnston, A. C. (1996), Seismic moment assessment of earthquakes in stable continental regions. III. New Madrid 1811-1812, Charleston 1886, and Lisbon 1755, Geophys. J. Int., 126, 314-344.
Kelson, K. I., G. D. Simpson, C. C. Haradan, W. R. Lettis, R. B. VanArdsdale, and J. B. Harris (1994), Multiple Holocene earthquakes along the Reelfoot fault, central New Madrid Seismic Zone, in Proceedings of the Workshop on Paleoseismology, U.S. Geol. Surv. Open File Rep., 94-568, 92-93.

Kenner, S. J., and P. Segall (2000), A mechanical model for intraplate earthquakes: Application to the New Madrid Seismic Zone, Science, 289, 2329-2332.

King, R. W., and Y. Bock (2001), Documentation for the GAMIT GPS software analysis, release 10.05, Mass. Inst. of Technol. Cambridge.

Kogan, M. G., G. M. Steblov, R. W. King, T. A. Herring, D. I. Frolov, S. G. Egorov, V. Y. Levin, A. Lerner-Lam, and A. Jones (2000), Geodetic constraints on the rigidity and relative motion of Eurasia and North America, Geophys. Res. Lett., 27, 2041-2044.

Langbein, J., and H. Johnson (1997), Correlated errors in geodetic time series: Implications for time-dependent deformation, J. Geophys. Res., 102, 591-603.

Liu, L., M. D. Zoback, and P. Segall (1992), Rapid intraplate strain accumulation in the New Madrid Seismic Zone, Science, 257, 1666-1669.

Mao, A., C. G. A. Harrison, and T. H. Dixon (1999), Noise in GPS coordinate time series, J. Geophys. Res., 104, 2797-2816.

Márquez-Azúa, B., and C. DeMets (2003), Crustal velocity field of Mexico from continuous GPS measurements, 1993 to June 2001: Implications for the neotectonics of Mexico, J. Geophys. Res., 108(B9), 2450, doi:10.1029/2002JB002241.

Mazzotti, S., and J. Adams (2005), Rates and uncertainties on seismic moment and deformation in eastern Canada, J. Geophys. Res., 110, B09301, doi:10.1029/2004JB003510.

Mazzotti, S., T. S. James, J. Henton, and J. Adams (2005), GPS crustal strain, postglacial rebound, and seismic hazard in eastern North America: The Saint Lawrence valley example, J. Geophys. Res., 110, B11301, doi:10.1029/2004JB003590.

McCarthy, D. D. (Ed.) (1996), IERS Standards 1996, IERS Tech. Note 21, Obs. de Paris, Paris, July .

Newman, A., S. Stein, J. Weber, J. Engeln, A. Mao, and T. Dixon (1999), Slow deformation and lower seismic hazard at the New Madrid Seismic Zone, Science, 284, 619-621.

Nocquet, J. M., E. Calais, and B. Parsons (2005), Geodetic constraints on glacial isostatic adjustment in Europe, Geophys. Res. Lett., 32, L06308, doi:10.1029/2004GL022174.

Nuttli, O. W. (1983), Catalog of central United States earthquakes since 1800 of $m_{b}>3.0$, St. Louis Univ., St. Louis, Mo.

Park, K., R. S. Nerem, J. L. Davis, M. S. Schenewerk, G. A. Milne, and J. X. Mitrovica (2002), Investigation of glacial isostatic adjustment in the northeast U.S. using GPS measurements, Geophys. Res. Lett., 29(11), 1509, doi:10.1029/2001GL013782.

Peltier, W. R. (1986), Deglaciation induced vertical motion of the North American continent and transient mantle rheology, J. Geophys. Res., 91 , 9099-9123

Peltier, W. R. (1994), Ice-age paleotopography, Science, 265, 195-201.

Peltier, W. R. (1996), Mantle viscosity and ice-age ice sheet topography, Science, 273, 1359-1364.

Peltier, W. R. (1998), A space geodetic target for mantle viscosity discrimination: Horizontal motions induced by glacial isostatic adjustment, Geophys. Res. Lett., 25, 543-546.

Peltier, W. R. (2004), Global glacial isostasy and the surface of the ice-age Earth: The ICE-5G (VM2) model and GRACE, Annu. Rev. Earth Planet. Sci., 32, 11149, doi:10.1146/annurev.earth.32.082503.144359.

Sella, G. F., T. H. Dixon, and A. Mao (2002), REVEL: A model for Recent plate velocities from space geodesy, J. Geophys. Res., 107(B4), 2081, doi:10.1029/2000JB000033.

Smalley, R., M. A. Ellis, J. Paul, and R. B. Van Arsdale (2005), Space geodetic evidence for rapid strain rates in the New Madrid Seismic Zone of central USA, Nature, 435, doi:10.1038/nature03642.

Snay, R. A., J. F. Ni, and H. C. Neugebauer (1994), Geodetically derived strain across the northern New Madrid Seismic Zone, U.S. Geol. Surv. Prof. Pap., 1538-F.

Snay, R., G. Adams, M. Chin, S. Frakes, T. Soler, and N. Weston (2002), The synergistic CORS program continues to evolve, paper presented at ION-GPS 2002, Inst. of Navigat., Portland, Oreg., 24 -27 September . Stein, S., and R. Gordon (1984), Statistical tests of additional plate boundaries from plate motion inversions, Earth Planet. Sci. Lett. 69, 400-412

Stein, S., N. H. Sleep, R. J. Geller, S. C. Wang, and G. C. Kroeger (1979), Earthquakes along the passive margin of eastern Canada, Geophys. Res. Lett., 6, 537-540.

Stein, S., S. Cloetingh, N. Sleep, and R. Wortel (1989), Passive margin earthquakes, stresses, and rheology, in Earthquakes at North-Atlantic Passive Margins: Neotectonics and Postglacial Rebound, edited by S. Gregerson and P. Basham, pp. 231-260, Springer, New York. 
Tuttle, M. P., and E. S. Schweig (1995), Archaelogical and pedological evidence for large prehistoric earthquakes in the New Madrid Seismic Zone, central United States, Geology, 23, 253-256.

Tuttle, M. P., J. Collier, L. W. Wolf, and R. H. Cafferty (1999), New evidence for a large earthquake in the New Madrid Seismic Zone between AD 1400 and 1670, Geology, 27, 771-774.

Weber, J., S. Stein, and J. Engeln (1998), Estimation of strain accumulation in the New Madrid Seismic Zone from GPS geodesy, Tectonics, 17, $250-266$.

Williams, S. D. P. (2003), The effect of coloured noise on the uncertainties of rates estimated from geodetic time series, J. Geod., 76, 483-494, doi:10.1007/s00190-002-0283-4.

Williams, S. D. P., Y. Bock, P. Fang, P. Jamason, R. Nikolaidis, L. Prawirodirdjo, M. Miller, and D. Johnson (2004), Error analysis of continuous GPS position time series, J. Geophys. Res., 109, B03412, doi:10.1029/2003JB002741.

$\mathrm{Wu}$, P., and P. Johnston (2000), Can deglaciation trigger earthquakes in North America?, Geophys. Res. Lett., 27, 1323-1326.
Zhang, J., Y. Bock, H. Johnson, P. Fang, S. Williams, J. Genrich, S. Wdowinski, and J. Behr (1997), Southern California Permanent GPS geodetic array: Error analysis of daily position estimates and site velocities, $J$. Geophys. Res., 102, 18,035-18,055.

Zumberge, J. F., M. B. Heflin, D. C. Jefferson, M. M. Watkins, and F. H. Webb (1997), Precise point positioning for the efficient and robust analysis of GPS data from large networks, J. Geophys. Res., 102, 5005-5017.

E. Calais, Department of Earth and Atmospheric Sciences, Purdue University, West Lafayette, IN 47907, USA. (ecalais@purdue.edu)

C. DeMets, Department of Geology and Geophysics, University of Wisconsin, Madison, WI 53706, USA. (chuck@geology.wisc.edu)

J. Y. Han, Department of Geomatics, Purdue University, West Lafayette, IN 47907, USA. (han5@purdue.edu)

J. M. Nocquet, Centre National de la Recherche Scientifique, UMR6526 Géosciences Azur, 250 Rue A. Einstein, F-06560 Valbonne, France. (nocquet@geoazur.unice.fr) 